\title{
Wind forcing calibration and wave hindcast comparison using multiple reanalysis and merged satellite wind datasets
}

\author{
Stopa Justin ${ }^{1, *}$ \\ 1 UBO, IRD, CNRS, LOPS, Ifremer, Plouzane, France. \\ * Corresponding author : Justin Stopa, email address : justin.stopa@ifremer.fr
}

\begin{abstract}
:
Wave hindcasts are tools to study climate and are regularly used in offshore and coastal engineering applications. The growing number of wind datasets and reanalysis products create more opportunity for generating wave hindcasts. Each wind dataset or reanalysis product has different resolution, model implementation, and assimilation scheme and if the wave model implementation is not calibrated to the input wind field the resulting wave field can have large biases solely due to the wind. In this work, we calibrate the wind to wave growth parameter within the spectral wave model WAVEWATCH III for 10 reanalysis datasets and 2 datasets composed of merged satellite observations. The calibration is performed globally by minimizing the differences between altimeter wave height observations and the model output for the year of 2001. We place special emphasis on ensuring the largest sea states are well captured and are not underestimated because of the important engineering applications of these data. After the calibration we compare the datasets and find each product reproduces the average sea states similarly, but high sea states have large discrepancies. We demonstrate that the space-time distribution of the extreme waves are very different even after calibration. We summarize by providing recommendations of the most accurate wind datasets to generate wave hindcasts.
\end{abstract}

Highlights

- Wave hindcast errors can be reduced by proper calibration of the wind input. The wind-to-wave growth parameter is calibrated for 12 wind datasets using altimeters. After calibration the hindcasts are similar for Hs P50 but deviate for the Hs maximum. It is demonstrated that strong storms have large differences in the wave hindcasts. Recommendations of the better wind forcing products are summarized.

Keywords : Wave hindcast, WAVEWATCH III, Wave climate, COWCLIP, Extreme waves, Reanalysis inter-comparison 


\section{Introduction}

Understanding the wave climate is essential to understanding integrated ocean-atmosphere-wave interactions and mitigating damages caused by ocean surface waves. The design of structures in offshore and coastal regions is still largely based on data generated from wave hindcasts. This is due to the fact that they have high time and space resolution, are of high fidelity, and some are openly available (e.g. Rascle \& Ardhuin, 2013; Chawla et al., 2013; Perez et al., 2017). In remote areas with limited in-situ and remote sensing observations, wave hindcasts are an attractive option to understand the wave climate variability (Stopa et al., 2016b; Thomson et al., 2016). There are uncertainties in the input wind fields and these impact the wave field. For example the noted overestimation of the wind speeds in the Southern Ocean before 1994 creates distinct positive biases in the wave field (Chawla et al., 2013; Rascle \& Ardhuin, 2013; Stopa \& Cheung, 2014). Wave hindcasts are typically generated using reanalysis datasets because they are evenly spaced in time and have high resolution. There have been many successful implementations of reanalysis-driven wave hindcasts (e.g. Cox \& Swail, 2001; Caires \& Sterl, 2005; Chawla et al., 2013; Rascle \& Ardhuin, 2013; Perez et al., 2017)

There are a growing number of accurate wind products, creating more opportunity for generating wave hindcasts. Reanalysis assimilates observations into models, which sometimes consist of atmospheric, oceanic, land, and ice models, and generate evenly distributed global data. The first notable release of a comprehensive reanalysis dataset started with the National Center for Environmental Prediction (NCEP) reanalysis 1 (R1) (Kalnay et al., 1996). The European Center for Medium-Range Weather Forecasts (ECMWF) 15-year and 40-year reanalyzes (ERA15; ERA40) (Uppala et al., 2005) and the Japanese Meteorological Agency's (JMA) 25-year reanalysis (JRA25) Onogi et al. (2007) followed suit with improvements. These efforts established best practices to collect, manage, and archive observations that are the backbone of the reanalysis products (Kistler et al., 2001). Now most weather centers have released updated and improved reanalysis versions: the NCEP the climate forecast system (CFSR) 1979-present (version 1 \& 2) (Saha et al., 2010, 2014), the ECMWF ERA-Interim (ERAI) 1979-present (Dee et al., 2011), the JMA 55-year (JRA55) 1958present (Kobayashi et al., 2015), and the NASA Modern Era Retrospective-Analysis for Research and Applications v2 (MERRA) (Gelaro et al., 2017). Many of these datasets start in 1979 with the modern satellite era or when global radiosonde observations were established in 1958. In addition,

there are reanalysis datasets that are constrained by atmospheric pressure observations to recreate 
the entire 20th century such as the Cooperative Institute for Research in Environmental Sciences (CIRES) R20C (Compo et al., 2011) and the ECMWF ERA20C (Stickler et al., 2014). With the large amount of satellite wind observations from scatterometers and radiometers collected in the last 25 years there have been efforts to create merged and gridded products at regular time intervals (Atlas et al., 2011; Bentamy et al., 2016). As improvements to models, computing power increases, and better quality satellite observations become available it is expected that there will be continued efforts to generate reanalysis products every 5 to 10 years. Therefore there are many options to generate wave hindcasts and there need to be continual efforts to assess these products and their suitability to generate wave hindcasts (e.g. Caires et al., 2004; Stopa \& Cheung, 2014).

Each wind dataset has different space-time resolution and the reanalysis datasets have different physical parameterizations, assimilation schemes, and assimilate different observations. All of these aspects change the characteristics of the surface wind field and when used to force a model will generate different wave fields. To introduce this idea, probability density functions (PDF) and quantile-quantile (QQ) plots are given in Figure 1 for the near surface wind speed (U10) and the significant wave height $\left(H_{s}\right)$ using several of the noted datasets. It is clear the U10 PDFs are different especially for high wind speeds $\left(>25 \mathrm{~ms}^{-1}\right)$. When using the same wave model implementation as in Figure 1(d,e,f), the generated wave field may not be consistent with wind forcing (e.g. R20C has no occurrences of U10 $>35 \mathrm{~ms}^{-1}$ but has the largest sea states). The details of these plots will be discussed throughout the manuscript. Our first goal is to demonstrate that some biases in the wave field can be corrected by calibrating the wave model parameterization to the input wind field. Since the wave field is a smoothed version of the atmosphere, it is unclear how each of the differences in the forcing wind fields impact the wave field. Therefore, after calibration we compare the output wave fields to understand their differences. We place special emphasis on high sea states and provide recommendations of more accurate products to drive a wave hindcast.

The manuscript is organized as follows. In section 2, we describe the datasets, various reanalysis products, and wave model implementation used to create 1-year wave hindcasts. In section 3 , we calibrate the wave model parameterization to the different wind datasets by comparing $H_{s}$ to satellite altimeters for 2001. In section 4, we compare the 12 different calibrated one-year hindcasts to understand their behavior. Our recommendations and conclusions follow in section 5 . 


\section{Datasets and model implementation}

In this section the satellite and buoy observations, input wind fields, and model implementation are described.

\subsection{Observations: merged altimeter dataset and moored buoys}

The multi-platform altimeter product (abbreviated ALT herein), is quality controlled and calibrated between platforms and to moored buoys (Queffeulou \& Croize-Fillon, 2015). In this work we chose the year of 2001 for the analysis since all datasets overlapped during this period. In 2001, there are three altimeter platforms in orbit: European Remote Sensing 2 (ERS2) (19962011), TOPEX/Poseidon (TPX) (1993-2005), and Geosat Follow-on (GFO) (2000-2007). The multi-mission dataset is calibrated between platforms and we expect it to be a fairly homogeneous dataset. Since the $1-\mathrm{Hz}$ altimeter measurements capture the instantaneous $H_{s}$ it is an unfair comparison with the time-space averaged spectral wave model. Therefore we smooth the altimeter tracks for each platform within the wave model grid cell $\left(0.5^{\circ}\right)$ by taking a running mean of 5 -points since each platform has a spatial footprint of 7-10 km. This dataset includes calibrated $H_{s}$ and $\mathrm{U} 10$.

The National Data Buoy Center (NDBC) provides quality controlled wave data from their network. Our model implementation is at the global scale $(55 \mathrm{~km})$ so we chose buoys sufficiently far $(>30 \mathrm{~km})$ from the coastlines and located in deep water. In total there are 32 buoys that met our criteria and they grouped by regions: Hawaii (HAW): 51001, 51002, 51003, 51004; North Pacific (NoP): 46001, 46035, 46066; Northeast Pacific (NEP): 46002, 46005, 46006, 46011, 46012, 46014, 46022, 46023, 46025, 46028, 46042(2D), 46047, 46053, 46054, 46059, 46063; Gulf of Mexico (GoM): 42001(D), 42002(2D), 42003(2D), 42039(2D), 42040(2D); Northwest Atlantic (NWA): 41001, 41002, 41010, 44004. Only a select number of buoys have frequency-direction spectra (2D) available for comparison to the wave model as noted above. See Figure 7a for their locations, which are limited to the Northern Hemisphere near the United States coastlines. The frequency-direction wave spectra are created using the maximum entropy method (MEM) (Earle et al., 1999). The highest frequency adequately resolved by the buoys is $0.4 \mathrm{~Hz}$. The model spectra are interpolated in time and space to match the buoy observations. 


\subsection{Forcing fields: wind and sea ice datasets}

In the following subsections we will briefly describe the model forcing datasets used in this study consisting of reanalysis and merged satellite products. Reanalysis assimilate various in-situ and satellite observations using the same assimilation method and model settings. Some reanalysis assimilate data in 4 dimensions (4D-VAR: x,y,z,t) (e.g. Dee et al., 2011), while others use 3 dimensions (3D-VAR) ( $x, y, z)$ for an initialization time step followed by a short forecast (typically 6 hours) (e.g. Saha et al., 2010). Most of the reanalysis datasets, with the exception of CFSR, have prescribed sea ice concentrations from external sources such as radiometers and sea surface temperatures (e.g. Dee et al., 2011; Hirahara et al., 2014). We summarize pertinent information below and in Table 1. The readers are referred to each of the references for detail on each product.

\subsubsection{NCEP R1}

The NCEP R1 was the first long-term reanalysis and has been used in a wide array of studies (Kalnay et al., 1996; Kistler et al., 2001). This product starts in 1949 and continues to update the time series using the same model and assimilation scheme. The atmospheric model is spectral and uses a spherical grid spacing. The spatial resolution in atmospheric models is commonly specified by "T" followed by a number. R1 has a resolution of T62, $(210 \mathrm{~km})$ which indicates spectral triangular truncation at wavenumber 62 with a linear grid. R1 uses 3D-VAR.

\subsection{2. $E C M W F E R A 40$}

ERA40 is based on its predecessor ERA15 developed at ECMWF and uses 3D-VAR (Uppala et al., 2005). This system has a truncated Gaussian atmospheric model (T159, N80 nominally) $(140 \mathrm{~km})$; these data were re-gridded onto a regularly spaced longitude-latitude grid using a spline interpolation. This system includes a wave model which assimilates satellite altimeter observations, but this does not affect our independent simulations.

\subsubsection{JMA JRA25}

JMA25 is the first long-term atmospheric reanalysis produced by JMA (Onogi et al., 2007). It uses the JMA assimilation system and observations from satellites from centers world-wide, including the National Climatic Data Center (NODC) and ECMWF. The atmospheric model resolution is T106 $(125 \mathrm{~km})$ and uses 3D-VAR. Ice concentrations were included using the Special Sensor Microwave Imager (SSMI) and Scanning Multichannel Microwave Radiometer (SMMR). 


\subsubsection{NCEP CFSR}

The NCEP CFSR is a global coupled system composed of atmosphere, ocean, land, and ice models and begins with the modern satellite era 1979-2010 (v1) (Saha et al., 2010). The atmospheric resolution is $38 \mathrm{~km}$ (T382) and uses 3D-Var initialized every 6 hours. Version 2 starts in 2011 and has shown improvement in the product especially in the tropical regions, with increased resolution $22 \mathrm{~km}$ (T574) (Saha et al., 2014). CFSR uses 3D-VAR with assimilations being updated every 6 hours. CFSR is the only reanalysis product that has a dynamic sea ice model. It uses the elastic-viscous model of Hunke \& Dukowicz (1997).

\subsubsection{ECMWF ERAI}

The ECMWF ERAI improved atmospheric model and assimilation system compared to its predecessor ERA40 (Dee et al., 2011). ERAI established the 4D-VAR assimilation scheme used in reanalysis. The atmospheric model is $76 \mathrm{~km}$ (T255). This system contains a coupled waveatmosphere component and the wave model assimilates altimeter observations.

\subsubsection{JMA JRA55}

JRA55 is the JMA second official release of a reanalysis starting in 1958, when the use of global radiosondes were established (Kobayashi et al., 2015). This product improves many of the aspects for JRA25 by implementing 4D-VAR with variational bias correction for satellite radiances, including a new radiation scheme, and introducing greenhouse gases that vary with time. The atmospheric resolution is $62 \mathrm{~km}$ (T319). A notable impact to wave modeling is the inclusion of an embedded parametric model to best capture the intensity of the tropical cyclones using information for the best track database; it captures $95 \%$ of the events (Murakami, 2014).

\subsubsection{NASA MERRA (v2)}

The MERRA (v2) (called MERRA herein) is a NASA reanalysis that uses the Goddard Earth observing system Data assimilation System (GEOS) (Rienecker et al., 2011; Gelaro et al., 2017). One of the original goals of the project (v1) was to simulate the hydrological cycle correctly (Rienecker et al., 2011). The latest release of the product improves many aspects, including the model, observing system data, radiance assimilation, and the boundary conditions for sea surface temperature and sea ice concentration based on Reynolds et al. (2002). The atmospheric resolution is $55 \times 70 \mathrm{~km}$ and uses 3D-VAR with assimilations being updated every 6 hours. 


\subsubsection{CIRES R20C}

The NOAA Cooperative Institute for Research in Environmental Sciences (CIRES) Climate Diagnostics Center led an effort to produce a reanalysis dataset spanning the entire 20th century, assimilating only surface observations of air pressure and boundary conditions observed from monthly sea surface temperature and sea ice concentration (Compo et al., 2006, 2011). R20C has been extended to 1851 and has an advantage of not being subject to changes in the quality or quantity of data assimilated in the modern era. This reanalysis applies a Kalman filter for each 6-hour analysis pressure field (3D-VAR) with an atmospheric model of $200 \mathrm{~km}$ (T62).

\subsubsection{ECMWF ERA20C}

The ECMWF follows R20C practices and created a reanalysis for the 20th century (Stickler et al., 2014). In addition to atmospheric pressure, surface winds are assimilated into the reanalysis. It includes a coupled land and ocean wave model. The resolution is $125 \mathrm{~km}$ (T159) and uses a 4D-VAR assimilation scheme which is input approximately at $210 \mathrm{~km}$.

\subsubsection{NCAR CFDDA}

The National Center for Atmospheric Research (NCAR) Climate Four Dimensional Data Assimilation system (CFDDA) established a method to downscale a mesoscale model (Hahmann et al., 2010). NCAR produced a 21-year (1985-2005) reanalysis based on the NCEP Reanalysis 2 (R2) (Kanamitsu et al., 2002). The mesoscale model (MM5) is implemented at $40 \mathrm{~km}$ resolution using $4 \mathrm{D}$-VAR. We chose to include this reanalysis to give insights on using downscaling through a mesoscale model. Also, it uses a 4D-VAR instead of the other NCEP products which use 3D-VAR.

\subsubsection{RSS CCMP (v2)}

Remote Sensing Systems (RSS) produced a cross-calibrated multi-platform (CCMP) gridded surface vector winds at regularly spaced time interval (6 h) (Atlas et al., 2011). Data is combined from 7 radiometer missions, 2 scatterometer missions (QuikSCAT, ASCAT), moored buoys, and atmospheric models using a variational analysis method to produce global maps at $0.25^{\circ}(27 \mathrm{~km})$. The most recent release (v2) uses updated satellite observations compared to its predecessor (Atlas et al., 2011). We use sea ice concentrations from radiometers produced by Institut Francais pour la Recherch et lExploitation de la MER (IFREMER), making the forcing fields completely derived by satellite observations. The ice coverage is produced by using a transfer equation that relates the 
polarization difference to ice concentration (Kaleschke et al., 2001). The daily sea ice concentrations have an original spatial resolution of $12.5 \mathrm{~km}$ covering both poles. This dataset was used in an Arctic wave hindcast and captures the daily ice features well (Stopa et al., 2016b).

\subsubsection{IFREMER SCT}

IFREMER created a merged satellite product consisting of radiometers and scatterometers from 1992-2016 (Bentamy et al., 2016; Desbiolles et al., 2017). This product includes wind vectors from IFREMER (ERS-1 and ERS-2), NASA (QuikSCAT), and EUMETSAT (ASCAT-A, ASCAT-B), and radiometers from RSS (SSM/I SSMIS, and WindSat). The use of ancillary data sources such as radiometer data (SSMI, SSMIS, WindSat) and ERAI has enabled a blended product available at spatial resolution and every 6 hours with spatial resolution of $0.25^{\circ}(27 \mathrm{~km})$ by using optimal interpolation and kriging methods. Note that data contained in either CCMP or SCT has also been assimilated into the reanalysis datasets with the exclusion of R20C and ERA20C. Indeed CCMP and SCT use the same datasets but the geophysical model functions which relate the measured mean radar cross-section to U10 are different. CCMP uses the RSS GMF's which are expected to be more accurate for high wind speeds (e.g. Ricciardulli \& Wentz, 2015). We use the sea ice concentration dataset produced by Ifremer as input (like CCMP).

\subsection{Model implementation}

The wave datasets are generated using WAVEWATCH III version 5.16 (abbreviated WW3 herein). WW3 integrates the spectral wave action equation in space and time, with discretized wave numbers and directions. Conservative wave processes like propagation, represented by the local rate of change and spatial and spectral transport terms, are balanced by the nonconservative sources and sinks. We implement the same global model setup as Rascle \& Ardhuin (2013). The model has a spatial grid of $0.5^{\circ}$ in longitude and latitude covering $\left(78^{\circ} \mathrm{S}, 80^{\circ} \mathrm{N}\right)$ and $\left(0^{\circ} \mathrm{E}, 360^{\circ} \mathrm{E}\right)$, with spectra composed of 24 directions and 32 frequencies exponentially spaced from 0.037 to 0.7 $\mathrm{Hz}$ at an increment of $10 \%$. Obstructions such as islands smaller than the spatial resolution are accounted by apportioning the energy in the $\mathrm{x}$ and $\mathrm{y}$-directions (Chawla \& Tolman, 2008). The nonlinear wavewave interactions are modeled using the discrete interaction approximation (DIA) of Hasselmann et al. (1985). Dissipation due to bottom friction uses the SHOWEX formulation to parameterize sandy bottoms, here with a constant sand grain size of $0.2 \mathrm{~mm}$ (Ardhuin et al., 2003). The Ultimate Quickest third order propagation scheme is implemented along with garden sprinkler 
reduction (Tolman, 2002). All model simulations are forced with the listed wind fields and sea ice concentrations in Table 1.

We implement physical formulations that describe the wind input and dissipation of Ardhuin et al. (2010). This package of physical parameterizations performs well especially in terms of higher order moments of the wave spectrum and treatment of swell (Stopa et al., 2016a). One major advance when using this package is its treatment of swell which is described by a laminar-toturbulent boundary within the atmosphere and was formulated and calibrated by tracking swells from synthetic aperture radar (Ardhuin et al., 2009; Stopa et al., 2016c). The wind input is adapted from the Janssen (1991) formulation, with an important reduction of input at high frequencies necessary to achieve a balance with the whitecapping term. The original formulation from Janssen (1991) is written in terms of the wave action $N(k, \theta)$ for each wavenumber $(k)$ and direction $(\theta)$

$$
S_{i n}(k, \theta)=\beta_{M A X} \frac{\rho_{a}}{\rho_{w}} \frac{1}{\kappa^{2}} e^{Z} Z^{4}\left(\frac{u_{*}}{C}+z_{\alpha}\right)^{2} \cos ^{p_{i n}}\left(\theta-\theta_{u}\right) \sigma N(k, \theta)
$$

where $\rho_{a, w}$ are the atmosphere and water densities, $\kappa$ is the von Karman constant, $p_{i n}$ is a constant that controls the directional distribution of $S_{i n}, \sigma$ is the wave frequency, $z_{\alpha}$ is a wave age dependent tuning parameter, $u_{*}$ is the friction velocity, and $Z$ is a parameterized sea surface roughness. The term $\beta_{M A X}$ is a non-dimensional growth parameter that controls the wind to wave growth. In this work, we modify $\beta_{M A X}$ to reduce the overall significant wave height bias. It is expected that other variables such as the roughness length $\left(z_{\alpha}\right)$ or even parameters in the dissipation source term could be modified to reduce the errors associated with different wind forcing.

\section{Calibration and Validation}

In the following each wind dataset is optimally calibrated and then each 1-year hindcast is compared to the altimeter and buoy observations to establish their performance. Our goal is to establish the optimal $\beta_{M A X}$ that reduces the global sea state errors for the $0.5^{\circ}$ model implementation. There is a distinct seasonality in the $H_{s}$ ratios (model/altimeter) as shown in Chawla et al. (2013). Therefore we use a 1-year hindcast to avoid any over-fitting that would occur if a particular month or season was used. The year 2001 is used since all datasets overlap during this period, there are 3 altimeter platforms in operation, and it is the middle of the modern reanalysis period from 1979-2016. 


\subsection{Calibration}

As briefly discussed in the introduction, in Figure 1 there are notable differences of the wind products. The U10 PDFs have similar shapes and the PDF maximum is within 6 to $8 \mathrm{~ms}^{-1}$ (Figure 1a). For upper wind speeds (U10>25 ms ${ }^{-1}$ ), there are distinct differences and the maximum U10 ranges from 24 to $43 \mathrm{~ms}^{-1}$. The lower spatial resolution products (ERA40, ERA20C, R1) have less occurrences of high wind speeds, which is expected since they cannot resolve the fine scale features. The high resolution mesoscale model implemented by CFDDA has lower wind speeds near the mean and upper wind speeds relative to the other products and altimeters (Figure 1b). R20C with its $210 \mathrm{~km}$ spatial resolution consistently has higher wind speeds in the range $20<U 10<26$ $\mathrm{ms}^{-1}$ compared to the altimeters. In Figure 1b, near the U10 average, most datasets are shifted to the left of the altimeter. The geophysical model function (GMF) relates the measured satellite normalized radar cross section (NRCS) of the altimeter to estimate U10. When waves are present this 1-parameter fit can result in an overestimation of U10 (Gourrion et al., 2002). The U10 from ALT deviates from all other products near the 5th through 30 percentile. It is expected that this systematic over-estimation of the derived U10 from altimeters at low-wind speeds causes the shift in the PDF relative to the other datasets. The cause of the overestimated U10 from altimeters under light wind speeds $\left(<4 \mathrm{~ms}^{-1}\right)$ could be due to specular reflection of the nadir-looking altimeter and/or sea state impact to the radar cross section. Notice that when U10> $8 \mathrm{~ms}^{-1}$ CFSR, CCMP, and SCT more closely match the observations. The same data is plotted in QQ plots in Figure 1c. It is clear most products have reduced wind speeds relative to the altimeters in the range $(3,10)$ $\mathrm{ms}^{-1}$ and when U10> $12 \mathrm{~ms}^{-1}$ the products begin to deviate from each other with the most drastic deviation when U10> $20 \mathrm{~ms}^{-1}$. CFSR and CCMP perform well, with their U10 within $0.5 \mathrm{~ms}^{-1}$ of the altimeter observations even at the 99th percentile.

The growth parameter $\beta_{M A X}$ is arbitrarily set to 1.45 for all hindcasts in Figure 1d,e,f. There are some consistent features between the $\mathrm{U} 10$ and $H_{s}$ PDFs. The coarser spatial resolution products (R1, ERA40, JRA25, ERA20C, ERAI) also have lower $H_{s}$. In Figure 1d the shapes of the PDFs are similar and the mean is within $[1.5,2.2] \mathrm{m}$. CFDDA has a higher occurrence of small wave heights, while R20C has the lowest occurrence of small wave heights when $H_{s}<1.5 \mathrm{~m}$. When $H_{s}>5.6 \mathrm{~m}, \mathrm{R} 20 \mathrm{C}$ systematically has the largest probability relative to all other hindcasts. Even though CCMP and SCT both incorporate data from scatterometers, they use different GMFs, and these differences are clearly seen in the wave heights. When comparing to the altimeters (Figure 
1e), most datasets follow the features seen in the winds and the PDFs are shifted the left of the altimeters close to the average sea states $\left(1<H_{s}<2.2 \mathrm{~m}\right)$. We have more confidence in the $H_{s}$ from altimeters, so most of the forcing wind products might indeed have difficulties in estimating calm wind speeds, which also contributes to the differences observed in the U10 PDFs (Figure 1b). The calm winds located in the tropics are expected to have larger uncertainties (Saha et al., 2014). The QQ plot (Figure 1f) shows a wide range of the wave heights from the hindcasts. So simply using the same $\beta_{M A X}$ for every input wind dataset results in a wide range of $H_{s}$ errors. For the highest sea states $\left(H_{s}>10 \mathrm{~m}\right.$ the 99.9 percentile), R1, ERA40, ERAI, ERA20C underestimate $H_{s}$ and JRA55, CCMP, and R20C overestimate $H_{s}$ when $\beta_{M A X}=1.45$.

Using CFSR as an example, $\beta_{M A X}$ is varied and the corresponding $H_{s}$ PDFs and QQ plots colocated with ALT are given in Figure 2. It is clear that larger values of $\beta_{M A X}$ result in taller wave heights. Our goal is to optimally determine the value for $\beta_{M A X}$ where the $H_{s}$ PDFs output from the wave model and the altimeter observations best align. The optimal $\beta_{M A X}$ is determined for each dataset by searching the entire space of $\beta_{M A X}$, which is typically within [1.0,2.1], with the exception of CFDDA. We require the 50 percentile (P50) and P99 of the significant wave height are well matched between the hindcasts and the altimeters: $\left(-0.1 \mathrm{~m}<P 50,9_{W W 3, H s}-P 50,99_{A L T, H s}<0.1\right.$ m) and require that P99 does not underestimate $H_{s}$. This second criteria is due to the important engineering applications of capturing the extreme wave heights. In general, we place more emphasis on capturing the largest sea states often at the expense of moderate seas. In this example (Figure 2), the hindcast using $\beta_{M A X}=1.385$ best matches the P50, P99, and the upper wave heights $\left(H_{s}>10\right.$ $\mathrm{m}$ ). In the $\mathrm{QQ}$ plot (Figure $2 \mathrm{~b}) \beta_{M A X}=1.385$ closely fits the bisector line.

In Figure 3, we objectively adjust $\beta_{M A X}$ to determine the optimal value to reduce $H_{s}$ residuals of the P50 and P99. These plots show $\beta_{M A X}$ (x-axis) versus various percentile differences (WW3ALT) and the root means square error. The coarser resolution products such as R1, ERA40, ERA20C have optimal performance when $\beta_{M A X}$ is larger $(>1.7)$. On the other hand, the higher resolution products such as CFSR, CCMP, and SCT have lower values for $\beta_{M A X}$. But in general this is not a rule since R20C with $210 \mathrm{~km}$ spatial resolution has an optimal performance when $\beta_{M A X}$ is close to 1.10. An ideal behavior is when all percentiles intersect with negligible residual; this means the PDFs are well matched for all sea states. Therefore ERA40, CFSR, ERAI, CCMP, and SCT all have good agreement with the altimeters for the majority of the sea states. The only datasets which do not match our criteria of having $H_{s}$ residuals $\pm 10 \mathrm{~cm}$ are R20C and CFDDA. For 
R20C the median residual is underestimated by $12 \mathrm{~cm}$ and the P99 residual overestimated by 15 $\mathrm{cm}$. For CFDDA, we chose $\beta_{\text {MAX }}=2.55$ because the RMSE has a very subtle minimum. We tested larger values of $\beta_{M A X}$ (up to 3.5) to get a better match of the extreme seas, but the PDFs did not resemble the altimeter observations. Clearly this dataset is not suitable to drive a wave hindcast. These plots can be used to understand how to calibrate the models for different applications. For example, to study the average sea states different criteria can be implemented. It is important to reinforce the fact that these charts are valid for the spatial resolution of $0.5^{\circ}$ and applicable for a global implementation. Models with different spatial resolution and coverage will need refinement and possible re-calibration.

\subsection{Validation}

The optimal $\beta_{M A X}$ values are given in Table 2 and are chosen from Figure 3. Here we summarize the overall performance of the 12 1-year hindcasts that use different wind forcing. We compute standard error metrics: the bias, root mean square error (RMSE), scatter index (SI), and slope of the linear regression (see Stopa et al. (2016a) for equations). There are clear differences in the performance of the older reanalysis datasets (R1, ERA40, JR25, and CFDDA) compared to the recent reanalysis datasets (CFSR, ERAI, JRA55, and MERRA). The older reanalysis (R1, ERA40, JRA25, CFDDA) have higher RMSEs and SIs of $>0.43 \mathrm{~m}$ and $>15 \%$ compared to $<0.41 \mathrm{~m}$ and $<15 \%$ for more recent reanalysis (CFSR, ERAI, JRA55, and MERRA). The 20th century reanalysis datasets (R20C and ERA20C) perform worse than the other reanalysis datasets. Both R20C and ERA20C have similar error metrics. R20C underestimates the $H_{s}$ but has slightly better match of the linear regression slope. Both of the merged satellite-observation datasets (CCMP and SCT) perform well with RMSE $<35 \mathrm{~cm}$ and SI $<13 \%$.

We generate similar error metrics for the extreme sea states $\left(H_{s}>10 \mathrm{~m}\right)$; the values are provided in parenthesis in Table 2. The performance of all hindcasts degrade at the extremes. All hindcasts have $H_{s}$ RMSEs that exceed $1 \mathrm{~m}$ and some have biases that underestimate $H_{s}$ by at least $1.5 \mathrm{~m}$, such as R1, CFDDA, R20C, ERA20C. The hindcasts that best capture the largest waves are CFSR, MERRA, CCMP, and SCT, shown by the RMSEs $<1.5 \mathrm{~m}$ and linear regression slopes between 0.88 and 1.14. ERAI is a precise forcing wind field $(\mathrm{SI}<10 \%)$, but underestimates the largest heights as reported by others (Rascle \& Ardhuin, 2013; Stopa \& Cheung, 2014). CFDDA is out of the reasonable range and significantly underestimates the largest waves. 
The PDFs and QQ plots are given in Figure 4 after calibration to complement Figure 1 . Now the $H_{s}$ PDFs (Figure 4a,b) closely resemble each other and the altimeter observations with the exception of CFDDA. At the extreme sea states the lower resolution products (R1, ERA20C, ERA40) still have reduced probability relative to the others and altimeter observations. The QQ plots are relatively close for all products and deviate less than $0.5 \mathrm{~m} \mathrm{up} H_{s}=8.4 \mathrm{~m}(\mathrm{P} 99.5)$. Notice we calibrated $\beta_{M A X}$ at P99 and required all products do not underestimate $H_{s}$. At the largest quantile shown (P99.9) the $H_{s}$ range is about $1 \mathrm{~m}$ between products.

Often in engineering and oceanographic applications other variables besides $H_{s}$, such as the wave period and direction, are important. We use the buoys from the NDBC network to compare $H_{s}$, average wave periods $(T m 02)$

$$
T m 02=\sqrt{m_{0} / m_{2}}
$$

where $m_{i}=\int_{0.037}^{0.4}(2 \pi f)^{i} E(f) d f$ is a frequency $(f)$ moment of the wave spectrum $(E)$ and the average wave direction $\left(\theta_{\text {avr }}\right)$

$$
\theta_{\text {avr }}=\arctan \left(\frac{\int_{0.037}^{0.4} \int_{0}^{2 \pi} \sin (\theta) E(f, \theta)}{\int_{0.037}^{0.4} \int_{0}^{2 \pi} \cos (\theta) E(f, \theta)}\right) .
$$

We truncate the integration of the buoys at $0.4 \mathrm{~Hz}$ since beyond this frequency the data is often noisy. We use the same frequency range in the wave model output to ensure a fair comparison between the computed parameters.

The results summarized in Table 3. The RMSEs and SIs are given for both the $H_{s}$ and $T m 02$. For $\theta_{\text {avr }}$ the RMSE is reported as well as the normalized standard deviation NSTD

$$
N S T D=\left(\frac{s t d\left(\theta_{\text {avr }, \text { hindcast }}\right)}{s t d\left(\theta_{\text {avr }, \text { buoy }}\right)}-1\right) \times 100
$$

where std is the standard deviation and the $N S T D$ is given in a percentage. Note that we are using circular mathematics for the $\theta_{\text {avr }}$ error metrics. We see the $H_{s}$ RMSEs are typically between 0.2 and $0.6 \mathrm{~m}$ and the SIs are between 9 and 37\%. For Tm02 the RMSEs are between 0.7 and $1.7 \mathrm{~s}$ and the SIs are typically between 6 and 20\%. Nearly all the hindcasts have $\theta_{\text {avr }}$ RMSEs of $30^{\circ}$ for the Northeast Pacific and $50^{\circ}$ in the Gulf of Mexico. Therefore the directional components of the wave model need improvement similar to the findings of Stopa et al. (2016a). The $\theta_{\text {avr }}$ NSTDs of the hindcasts are typically 0 to $43 \%$ less than the buoy observations. This means the directional components are relatively smooth compared to the observations; this is particularly true for the Northeast Pacific. In the Northeast Pacific and Gulf of Mexico the hindcasts are performing the 
worst with the largest $H_{s}$ and Tm02 RMSEs. In the Gulf of Mexico the $\theta_{\text {avr }}$ RMSEs are large, and possibly small scale atmospheric features are not well captured by the products. Notice ERAI has some of the lowest SIs for both $H_{s}$ and $T m 02$, demonstrating it is a precise forcing wind field. CFSR systematically has the lowest RMSEs and SIs for Tm02. Some other credible forcing fields are modern reanalyzes (CFSR, JRA55, MERRA) and the satellite datasets (CCMP and SCT).

The spatial view of the hindcast performances relative to ALT are given in Figures 5 and 6 for the normalized RMSE (NRMSE) and the SI respectively. These error metrics show the hindcasts' accuracy and precision respectively. The wave hindcasts are interpolated in space and time to match the altimeters and the error metrics are computed in $2^{\circ}$ bins for each 1 -year hindcast. For the NRMSE (Figure 5), it is clear that R1, R20C, ERA20C, and CFDDA have worse performance compared to the other products since the NRMSE is often $>15 \%$. It is interesting to note that the older reanalysis datasets such as ERA40 and JRA25 perform reasonably well once they are properly calibrated. However, their performance is worse than their successors ERAI and JRA55 respectively. JRA55 has larger errors in the tropics compared to the other recent hindcasts (CFSR, ERAI, and MERRA). ERA20C and R20C have similar spatial patterns and clearly have improved performance in the Northern Hemisphere (NH) compared to the Southern Hemisphere (SH). This is expected since the majority of the pressure observations were recorded in the NH. CFSR, ERAI, JRA55, MERRA, CCMP, and SCT all perform well. CCMP has the best performance with approximately $68 \%$ of the oceans having a NRMSE $<8 \%$ with a close second to SCT at $65 \%$. CSFR and MERRA and have best performance and have NRSMEs less than $8 \%$ for 62 and $58 \%$ of the oceans respectively.

The corresponding plots for the SI are given in Figure 6. R1, CFDDA, R20C, and ER20C have worse performance than the other hindcasts with SI $>15 \%$. R20C and ERA20C have lower precision (higher SIs) in the SH. The SIs are less than $10 \%$ in the majority of the oceans for CFSR, ERAI, JRA55, MERRA, CCMP, and SCT. CCMP, SCT, CFSR, and MERRA are the top 4 best forcing fields with SIs less than $10 \%$ for $87,86,82$, and $79 \%$ of the oceans respectively. In general, all wave hindcasts have larger NRMSEs and SIs that are typically 2-5\% higher near the Equator compared to surrounding regions. In addition, near the ice edge in the Southern Ocean all hindcasts have larger errors, and these features are more pronounced in the older reanalysis products like R1, ERA40, and JRA25. Therefore either ice edge location and/or the atmospheric models are performing better in the more recent reanalysis datasets (CFSR, ERAI, JRA55, MERRA). 


\section{Comparison and extremes}

To assess the different hindcasts we compute the average and standard deviation of different statistics from the ensemble (Figure 7). In this analysis we remove CFDDA since this hindcast was not in the reasonable range compared to the observations. The median in Figure 7a,b shows the SH has larger sea states than the NH. More importantly, the variability shown by the standard deviation of these 11 hindcasts is typically less than $30 \mathrm{~cm}$ globally. In fact $68 \%, 88 \%$, and $97 \%$ of the ocean has standard deviation less than 10, 15, and $20 \mathrm{~cm}$ respectively. Note that in Pacific near the Equator there is a region with standard deviations of 10 to $20 \mathrm{~cm}$ and the $H_{s}$ P50 is only $1.5 \mathrm{~m}$. So this region has a large relative variability (approx. 15\%) compared to the extra-tropics $(<5 \%)$. For $H_{s}$ P95 (Figure $7 \mathrm{c}, \mathrm{d}$ ), the $\mathrm{NH}$ and $\mathrm{SH}$ now have similar magnitudes with maximum in the Indian Ocean sector of the Southern Ocean. The magnitude of $H_{s}$ P95 is relatively smooth and the standard deviation is mostly less than $20 \mathrm{~cm}$. Specifically $64 \%, 90 \%$, and $97 \%$ of the ocean has standard deviations less than 20,30, and $40 \mathrm{~cm}$ respectively. The maximum $H_{s}$ in Figure $7 \mathrm{e}, \mathrm{f}$ does not have a smooth pattern, and impact from individual storms can be identified. The standard deviation shows particular events can have very large $H_{s}$ differences exceeding $2.5 \mathrm{~m}$. In the lower latitudes, the standard deviations of the hindcasts are less than $50 \mathrm{~cm}$ with the exception of tropical cyclone regions that are most notable in the Western Pacific and Atlantic. Most of the variability is in the extra tropics, and it is common to have standard deviations greater than $1 \mathrm{~m}$. The maximum $H_{s}$ differences come from variations in the magnitude of the forcing wind fields or space-time deviations of the storm locations.

In short, all hindcasts reproduce the average sea state conditions within $10 \mathrm{~cm}$ of each other; even the $H_{s}$ P95 is well matched between hindcasts. The largest sea states have greater variability between the hindcasts, and these differences are quantified by calculating the occurrence of $H_{s}>10$ m (based on hourly data). The results are presented in Figure 8. It is clear that the extra-tropics have the strongest and most persistent storms. Tropical cyclones can indeed breach this threshold, but their occurrence is low compared to extra-tropical events. R1, ERA40, and JRA25 have similar patterns. JRA25 has slightly larger waves in both hemispheres. CFDDA is not applicable to capture these high sea states, and most of the ocean has $H_{s}<10 \mathrm{~m}$. CFSR, ERAI, JRA55, and MERRA have similar spatial patterns. ERAI has the least energy at high sea states, and it is known that ERAI underestimates these conditions (Stopa \& Cheung, 2014). In the SH, CFSR has reduced seas compared to JRA55 and MERRA. In the NH, MERRA and CFSR have similar occurrence 
of $H_{s}>10 \mathrm{~m}$, but JRA55 has less occurrences of elevated seas. R20C and ERA20C have similar patterns; however R20C has more occurrences of elevated seas in the SH especially in the Indian Ocean; and perhaps this is too high with respect to the other hindcasts. CCMP and SCT have nearly the same pattern with slightly more wave activity in SCT. Notice the consistency between the products produced by the same centers: NCEP (R1, CSFSR, R20C), ECWMF (ERA40, ERAI, ERA20C), and JMA (JRA25, JRA55). The recently released products have higher occurrence of elevated wave heights $\left(H_{s}>10 \mathrm{~m}\right)$, which is due to the fact that the spatial resolution increases, physical parameterizations improve, and satellite observations at extremes improve.

It is clear that the bulk statistics are different for the upper wave heights so two particular storms are analyzed to further highlight the differences. The largest altimeter record for $2001\left(H_{s}>16 \mathrm{~m}\right)$ was recorded in a Southern Ocean extra-tropical storm by GFO. This storm from April 10 to April 13 traveled south of Australia in the Southern Ocean (Figure 9a). As the storm intensified on April 10 at 17:00, the spatial patterns of the $H_{s}$ exceeding $9 \mathrm{~m}$ are different for each hindcast (Figure 9c). ERA40 has the smallest spatial coverage of $H_{s}>9 \mathrm{~m}$ at $1.6 \times 10^{5} \mathrm{~km}^{2}$, while most hindcasts (JRA25, CFSR, ERAI, R20C, ERA20C, and SCT) have areas with $H_{s}>9 \mathrm{~m}$ within $2.8-3.8 \times 10^{5}$ $\mathrm{km}^{2}$. R1, JR55, MERRA, and CCMP have enhanced sea states with regions of $H_{s}>9$ m exceeding $4 \times 10^{5} \mathrm{~km}^{2}$ and $H_{s}$ larger than $12 \mathrm{~m}$. Notice that nearly all hindcasts have the storm in nearly the same position. The exception is R1, which places the storm slightly ahead of the others.

When the storm is nearly at its peak intensity, GFO crosses the storm center on April 12 at 03:45. The storm contours are given in Figure 9d and all hindcasts have the storm in the same position with the exception of R1. The spatial coverage of $H_{s}>9 \mathrm{~m}$ between hindcasts varies by $7 \times 10^{5} \mathrm{~km}^{2}$ with maximum being R20C and minimum ERA40. The altimeter observations in Figure $9 \mathrm{~b}$ give insight to which models best capture the maximum $H_{s}$ and spatial extent of the storm waves. It is confirmed that storm location in R1 is incorrect. Ignoring CFDDA and R1, the hindcasts have the maximum $H_{s}$ ranging from 12 to $18 \mathrm{~m}$ for this event. JRA55 captures the maximum of the storm very well with only a small displacement to the South. MERRA is the only hindcast that overestimates the peak of the event by $1.3 \mathrm{~m}$. In addition JRA25, R20C, ERA20C perform well and underestimate the altimeter $H_{s}$ of $16.4 \mathrm{~m}$ by $50 \mathrm{~cm}$. ERAI, CCMP, and SCT moderately underestimate the peak $H_{s}$ by 1-2 m while CFSR and ERA40 unreasonably underestimates the peak $H_{s}$ by $3 \mathrm{~m}$. Towards the end of the event, on April 12 at 22:00, there is large variability in the spatial coverage of $H_{s}>9 \mathrm{~m}$ that exceeds $6 \times 10^{6} \mathrm{~km}^{2}$ between hindcasts 
(Figure 9e). Some hindcasts fall below the $H_{s}$ threshold of $9 \mathrm{~m}$ and are not plotted. The time evolution of the maximum $H_{s}$ and area of $H_{s}>9 \mathrm{~m}$ are given in Figure 9f,g. It is clear that towards the end of the storm there is more variability in the spatial distribution of the largest waves. Also notice that the hindcasts have maximum $H_{s}$ that vary from 4 to $8 \mathrm{~m}$ for the duration of the event.

In Figure $7 \mathrm{f}$ it is clear that regions affected by tropical cyclones have larger variability with $H_{s}$ standard deviations exceeding $2 \mathrm{~m}$. We pick the tropical cyclone Utor in the Western Pacific near the Philippines that occurred July 1-5 to demonstrate the large variability of the hindcasts under extreme tropical cyclone wind forcing. This event is clearly seen in Figure 7c. Utor grazed the island of Lazon in the Philippines and then made landfall in Southeast China on July 6. The cyclone overview is given in Figure 10a. There was a TPX pass that intersected the storm center on July 3 07:11. The spatial distribution of the $H_{s}>8 \mathrm{~m}$ on July 2 is similar for the various hindcasts and the $H_{s}=8 \mathrm{~m}$ contours have a "C" pattern (Figure 10c). Note that R1 has the storm in different location relative to the other hindcasts, similar to the last case.

When TPX crosses the storm on July 3 in Figure 10b there is a large range of $H_{s}$ profiles. MERRA overestimates $H_{s}$ and it is confirmed that the location of Utor in R1 is mis-located compared to the altimeter observations. In this case, ERAI best matches the TPX $H_{s}$ but with an underestimation of $1 \mathrm{~m}$. All other hindcasts (ERA40, JRA25, CFSR, JRA55, CFDDA, R20C, ERA20C, CCMP, and SCT) underestimate the maximum $H_{s}$ of the event $\left(H_{s}=11.2 \mathrm{~m}\right)$ by 2 to $5 \mathrm{~m}$. The positions of the storm in ERA40, CCMP, ERAI, and MERRA are approximately correct since the $H_{s}$ profiles follow the TPX observations. The spatial coverage of $H_{s}>8 \mathrm{~m}$ varies greatly between products $10 \times 10^{5} \mathrm{~km}^{2}$ (Figure 10c,d,e,g). Towards the end of the event and as the storm moves into the South China Sea, the spatial patterns of $H_{s}>8 \mathrm{~m}$ vary by $3 \times 10^{5} \mathrm{~km}^{2}$. Figure 10f,g shows the time series of the maximum $H_{s}$ and storm area with $H_{s}>8 \mathrm{~m}$. It is clear that the maximum $H_{s}$ has a large variability between products. Of course some products like R20C and ERA20C are not specifically designed to capture the small-scale features of tropical cyclones. This particular example shows that the range in $H_{s}$ can be $8 \mathrm{~m}$ between the hindcasts. Therefore extreme caution should be used when using these hindcasts to understand extreme sea states, especially for tropical cyclones. 


\section{Discussion and Recommendations}

In this work we calibrated 12 different wind products by adjusting the $\beta_{M A X}$ parameter that describes the wind to wave growth in the Janssen (1991) formulation. We demonstrate that modifying $\beta_{M A X}$ reduces errors in the wave field. This is due to the fact that each wind product has different characteristics. This exercise was performed on a $0.5^{\circ}$ global grid, and we used altimeter observations as reference for the calibration. Then we compare the hindcasts to NDBC moored buoys to assess $H_{s}, T m 02$, and $\theta_{\text {avr }}$. Our procedure can be adapted to regional domains with different resolutions. However, one should take caution when applying this approach, especially with a sufficiently small domain, because $\beta_{M A X}$ could be incorrectly compensating for missing or improper model parameterizations.

Our criteria was to best match the $H_{s}$ PDFs, and we ensured the largest sea states $>$ P99 are not underestimated. We specifically summarize the advantages and disadvantages of each hindcast in Table 4 and here we generalize the conclusions. After calibration, even the older reanalysis datasets, such as R1, ERA40, and JRA25, perform well with respect to bulk statistics. Our results clearly demonstrate that the more recent reanalysis wind fields from CFSR, ERAI, JRA55, and MERRA are better forcing wind fields for wave hindcasting compared to their predecessors. The NCEP 4DVAR reanalysis that uses a mesoscale model, CFDDA, is not suitable for wave hindcasting. This wind forcing cannot capture the high sea states; there is an extreme underestimation. The 20th century reanalysis datasets R20C and ERA20C have similar performance. These hindcasts do not perform as well as the higher resolution products and have less fidelity than the other hindcasts. However, it is important to note that they capture the magnitude of the extreme events especially in the extra tropics. R20C and ERA20C poorly capture tropical cyclones. The hindcasts driven by satellite observations (CCMP and SCT) perform well and are as good if not better than the reanalysis products. However, their 6-hour time step might not be sufficient for some cases, such as rapidly intensifying storms.

The buoy comparison gives an independent check of the calibrated wave hindcasts. The $H_{s}$ error metrics between the buoys and altimeters are similar; however, regional areas such as the Northeast Pacific and Gulf of Mexico have larger errors. The RMSEs for the Tm02 are typically 1 $\mathrm{s}$ and exceed $1.6 \mathrm{~s}$ in the Gulf of Mexico. All wave hindcasts have similar performance for average wave directions, which is most likely due to the same model source term parameterization and implementation of the DIA. In the Gulf of Mexico the $\theta_{\text {avr }}$ are poor with RMSEs of $50^{\circ}$, suggesting 
model improvements are needed to better capture the directionality of the wave field

All hindcasts have similar average sea states (P50), and the variability between hindcasts is negligible $(<5 \%)$. Even up to the 95th percentile, the variability between hindcasts is typically less than $10 \%$. The hindcasts deviate only at the largest sea states. Extra-tropical storms are well captured by the hindcasts. However, the variability for the largest events and the occurrence of these events varies greatly between products. For the example storms, the maximum $H_{s}$ can exceed $6 \mathrm{~m}$ for a large extra-tropical event and vary by $8 \mathrm{~m}$ for a tropical cyclone. For practical applications it is important to understand that each forcing wind field will give very different results for high sea states. Using an ensemble approach such as this to study extreme events will help quantify some of the uncertainty. In general it is clear that tropical cyclones are not well captured. Some of the reanalysis products are able to capture the tropical events better than others (Murakami, 2014; Hodges et al., 2017).

For wave hindcasting we recommend CFSR, ERAI, JRA55, MERRA, CCMP, and SCT. For extreme waves CFSR, JRA55, MERRA, CCMP, and SCT perform well in terms of bulk statistics. However, the case studies revealed that CFSR underestimated both of the peak $H_{s}$ events by 2-3 meters. On the other hand, ERAI has the storm in the correct position, but maximum $H_{s}$ was underestimated typically by $1 \mathrm{~m}$. ERAI reanalysis is one of the most precise forcing fields and the SIs from wave parameters are typically the lowest. JRA55 matches the extreme waves very well and is expected to better capture tropical cyclones since they are blended into the product through use of a parametric model Kobayashi et al. (2015); Murakami (2014). MERRA overestimates the largest waves. Of course $\beta_{M A X}$ can be reduced, but this affects the entire $H_{s}$ PDF (see Figure 3 ). A $\beta_{M A X}=1.45$ matches the peak $H_{s}$ of 16.4 and $11.1 \mathrm{~m}$ for the extra and tropical cases studies, but the overall error metrics degraded and a global underestimation was observed (not shown). Otherwise most of the hindcasts underestimate the extreme sea states.

For climate studies, the consistency of the products in time is key, and this is a topic of future work. Now with properly calibrated hindcasts this task can be performed more diligently. In particular, R20C and ERA20C might have the advantage of being less affected by changes in the quantity and quality of the assimilated data. Another critical point is the need for continual observations from scatterometers and radiometers, which provide a tremendous resource for the community. As the reanalysis products continually improve, there is a need to assess their ability to reproduce the wave field through hindcasts. Additional and improved measurements of the winds 
and increased spatial resolution will provide further insights and explanations of regions with large uncertainties especially, for high sea states.

\section{Acknowledgements}

This work is supported by LabexMER via grant ANR-10-LABX-19-01, EU-FP7 project SWARP under grant agreement 607476, and ONR grant number N0001416WX01117. I thank Fabrice Ardhuin and Alexis Mouche for their input of early versions of this work. I appreciate the three anonymous reviewers for their comments that have improved this paper. The altimeter dataset can be obtained from ftp.ifremer.fr/ifremer/cersat/products/swath/altimeters/waves/. The IFREMER/CERSAT SSMI daily ice concentrations are available from ftp.ifremer.fr/ifremer/cersat/. The NDBC buoy data can be accessed from www.ndbc.noaa.gov/. The R1, JRA25, ERA40, CFSR, ERAI, JRA55, and CFDDA wind fields and ice concentrations can be obtained from rda.ucar.edu. MERRAv2 wind fields and ice concentration can be obtained from gmao.gsfc.nasa.gov/reanalysis/MERRA2/. CCMPv2 is available via Remote Sensing Systems ftp2.remss.com/ccmp/. The Ifremer blended product of satellite wind observations (SCT) is available ftp.ifremer.fr/IFREMER_LOPS_blended_wind/longterm_analysi

\section{References}

Ardhuin, F., Chapron, B., \& Collard, F. (2009). Observation of swell dissipation across oceans. Geophysical Research Letters, 36. doi:10.1029/2008g1037030.

Ardhuin, F., Herbers, T. H. C., Jessen, P. F., \& O'Reilly, W. C. (2003). Swell transformation across the continental shelf. part II: Validation of a spectral energy balance equation. Journal of Physical Oceanography, 33, 1940-1953. doi:10.1175/1520-0485(2003)033<1940: statcs>2.0.co; 2.

Ardhuin, F., Rogers, E., Babanin, A. V., Filipot, J.-F., Magne, R., Roland, A., van der Westhuysen, A., Queffeulou, P., Lefevre, J.-M., Aouf, L., \& Collard, F. (2010). Semiempirical dissipation source functions for ocean waves. part i: Definition, calibration, and validation. Journal of Physical Oceanography, 40, 1917-1941. doi:10.1175/2010jpo4324.1.

Atlas, R., Hoffman, R. N., Ardizzone, J., Leidner, S. M., Jusem, J. C., Smith, D. K., \& Gombos, D. (2011). A cross-calibrated, multiplatform ocean surface wind velocity product for meteorological 
and oceanographic applications. Bulletin of the American Meteorological Society, 92, 157-174. doi:10.1175/2010bams2946.1.

Bentamy, A., Grodsky, S. A., Elyouncha, A., Chapron, B., \& Desbiolles, F. (2016). Homogenization of scatterometer wind retrievals. International Journal of Climatology, 37, 870-889. doi:10.1002/ joc. 4746

Caires, S., \& Sterl, A. (2005). A new nonparametric method to correct model data: Application to significant wave height from the ERA-40 re-analysis. Journal of Atmospheric and Oceanic Technology, 22, 443-459. doi:10.1175/jtech1707.1.

Caires, S., Sterl, A., Bidlot, J.-R., Graham, N., \& Swail, V. (2004). Intercomparison of different wind-wave reanalyses. Journal of Climate, 17, 1893-1913. doi:10.1175/1520-0442(2004) $017<1893$ : iodwr $>2.0 . \operatorname{co} ; 2$

Chawla, A., Spindler, D. M., \& Tolman, H. L. (2013). Validation of a thirty year wave hindcast using the climate forecast system reanalysis winds. Ocean Modelling, 70, 189-206. doi:10.1016/ j.ocemod.2012.07.005.

Chawla, A., \& Tolman, H. L. (2008). Obstruction grids for spectral wave models. Ocean Modelling, 22, 12-25. doi:10.1016/j.ocemod.2008.01.003.

Compo, G. P., Whitaker, J. S., \& Sardeshmukh, P. D. (2006). Feasibility of a 100-year reanalysis using only surface pressure data. Bulletin of the American Meteorological Society, 87, 175-190. doi:10.1175/bams-87-2-175.

Compo, G. P., Whitaker, J. S., Sardeshmukh, P. D., Matsui, N., Allan, R. J., Yin, X., Gleason, B. E., Vose, R. S., Rutledge, G., Bessemoulin, P., Brnnimann, S., Brunet, M., Crouthamel, R. I., Grant, A. N., Groisman, P. Y., Jones, P. D., Kruk, M. C., Kruger, A. C., Marshall, G. J., Maugeri, M., Mok, H. Y., Nordli, Ø., Ross, T. F., Trigo, R. M., Wang, X. L., Woodruff, S. D., \& Worley, S. J. (2011). The twentieth century reanalysis project. Quarterly Journal of the Royal Meteorological Society, 137, 1-28. doi:10.1002/qj.776.

Cox, A. T., \& Swail, V. R. (2001). A global wave hindcast over the period 1958-1997: Validation and climate assessment. Journal of Geophysical Research: Oceans, 106, 2313-2329. doi:10.1029/ $2001 \mathrm{jc000301.}$ 
Dee, D. P., Uppala, S. M., Simmons, A. J., Berrisford, P., Poli, P., Kobayashi, S., Andrae, U., Balmaseda, M. A., Balsamo, G., Bauer, P., Bechtold, P., Beljaars, A. C. M., van de Berg, L., Bidlot, J., Bormann, N., Delsol, C., Dragani, R., Fuentes, M., Geer, A. J., Haimberger, L., Healy, S. B., Hersbach, H., Hólm, E. V., Isaksen, L., Kållberg, P., Khler, M., Matricardi, M., McNally, A. P., Monge-Sanz, B. M., Morcrette, J.-J., Park, B.-K., Peubey, C., de Rosnay, P., Tavolato, C., Thépaut, J.-N., \& Vitart, F. (2011). The ERA-interim reanalysis: configuration and performance of the data assimilation system. Quarterly Journal of the Royal Meteorological Society, 137, 553-597. doi:10.1002/qj.828.

Desbiolles, F., Bentamy, A., Blanke, B., Roy, C., Mestas-Nuñez, A. M., Grodsky, S. A., Herbette, S., Cambon, G., \& Maes, C. (2017). Two decades 1992-2012 of surface wind analyses based on satellite scatterometer observations. Journal of Marine Systems, 168, 38-56. doi:10.1016/j . jmarsys.2017.01.003.

Earle, M., Steele, K., \& Wang, D. (1999). Use of advanced directional wave spectra analysis methods. Ocean Engineering, 26, 1421-1434. doi:10.1016/s0029-8018(99)00010-4.

Gelaro, R., McCarty, W., Suárez, M. J., Todling, R., Molod, A., Takacs, L., Randles, C. A., Darmenov, A., Bosilovich, M. G., Reichle, R., Wargan, K., Coy, L., Cullather, R., Draper, C., Akella, S., Buchard, V., Conaty, A., da Silva, A. M., Gu, W., Kim, G.-K., Koster, R., Lucchesi, R., Merkova, D., Nielsen, J. E., Partyka, G., Pawson, S., Putman, W., Rienecker, M., Schubert, S. D., Sienkiewicz, M., \& Zhao, B. (2017). The modern-era retrospective analysis for research and applications, version 2 (MERRA-2). Journal of Climate, 30, 5419-5454. doi:10. 1175/jcli-d-16-0758.1.

Gourrion, J., Vandemark, D., Bailey, S., Chapron, B., Gommenginger, G. P., Challenor, P. G., \& Srokosz, M. A. (2002). A two-parameter wind speed algorithm for ku-band altimeters. Journal of Atmospheric and Oceanic Technology, 19, 2030-2048. doi:10.1175/1520-0426(2002)019<2030: atpwsa>2 .0.co;2.

Hahmann, A. N., Rostkier-Edelstein, D., Warner, T. T., Vandenberghe, F., Liu, Y., Babarsky, R., \& Swerdlin, S. P. (2010). A reanalysis system for the generation of mesoscale climatographies. Journal of Applied Meteorology and Climatology, 49, 954-972. doi:10.1175/2009jamc2351.1. 
Hasselmann, S., Hasselmann, K., Allender, J. H., \& Barnett, T. P. (1985). Computations and parameterizations of the nonlinear energy transfer in a gravity-wave specturm. part II: Parameterizations of the nonlinear energy transfer for application in wave models. Journal of Physical Oceanography, 15 , 1378-1391. doi:10.1175/1520-0485(1985) 015<1378: capotn>2.0.co;2.

Hirahara, S., Ishii, M., \& Fukuda, Y. (2014). Centennial-scale sea surface temperature analysis and its uncertainty. Journal of Climate, 27, 57-75. doi:10.1175/jcli-d-12-00837.1.

Hodges, K., Cobb, A., \& Vidale, P. L. (2017). How well are tropical cyclones represented in reanalysis datasets? Journal of Climate, 30, 5243-5264. doi:10.1175/jcli-d-16-0557.1.

Hunke, E. C., \& Dukowicz, J. K. (1997). An elastic-viscous-plastic model for sea ice dynamics. Journal of Physical Oceanography, 27, 1849-1867. doi:10.1175/1520-0485(1997) 027<1849: aevpmf $>2.0 . \operatorname{co} ; 2$.

Janssen, P. A. E. M. (1991). Quasi-linear theory of wind-wave generation applied to wave forecasting. Journal of Physical Oceanography, 21, 1631-1642. doi:10.1175/1520-0485(1991) $021<1631$ : qltoww $>2.0$. co; 2 .

Kaleschke, L., Lpkes, C., Vihma, T., Haarpaintner, J., Bochert, A., Hartmann, J., \& Heygster, G. (2001). SSM/i sea ice remote sensing for mesoscale ocean-atmosphere interaction analysis. Canadian Journal of Remote Sensing, 27, 526-537. doi:10.1080/07038992.2001.10854892.

Kalnay, E., Kanamitsu, M., Kistler, R., Collins, W., Deaven, D., Gandin, L., Iredell, M., Saha, S., White, G., Woollen, J., Zhu, Y., Leetmaa, A., Reynolds, R., Chelliah, M., Ebisuzaki, W., Higgins, W., Janowiak, J., Mo, K. C., Ropelewski, C., Wang, J., Jenne, R., \& Joseph, D. (1996). The NCEP/NCAR 40-year reanalysis project. Bulletin of the American Meteorological Society, 77, 437-471. doi:10.1175/1520-0477(1996)077<0437: tnyrp>2.0.co; 2.

Kanamitsu, M., Ebisuzaki, W., Woollen, J., Yang, S.-K., Hnilo, J. J., Fiorino, M., \& Potter, G. L. (2002). NCEP-DOE AMIP-II reanalysis (r-2). Bulletin of the American Meteorological Society, 83, 1631-1643. doi:10.1175/bams-83-11-1631.

Kistler, R., Collins, W., Saha, S., White, G., Woollen, J., Kalnay, E., Chelliah, M., Ebisuzaki, W., Kanamitsu, M., Kousky, V., van den Dool, H., Jenne, R., \& Fiorino, M. (2001). The NCEP-NCAR 50-year reanalysis: Monthly means CD-ROM and documentation. Bulletin of 
the American Meteorological Society, 82, 247-267. doi:10.1175/1520-0477(2001)082<0247: tnnyrm $>2.3 . \operatorname{co} ; 2$

Kobayashi, S., Ota, Y., Harada, Y., Ebita, A., Moriya, M., Onoda, H., Onogi, K., Kamahori, H., Kobayashi, C., Endo, H., Miyaoka, K., \& Takahashi, K. (2015). The JRA-55 reanalysis: General specifications and basic characteristics. Journal of the Meteorological Society of Japan. Ser. II, 93, 5-48. doi:10.2151/jmsj.2015-001.

Molod, A., Takacs, L., Suarez, M., \& Bacmeister, J. (2015). Development of the GEOS-5 atmospheric general circulation model: evolution from merra to merra2. Geoscientific Model Development, 8, 1339-1356. doi:10.5194/gmd-8-1339-2015.

Murakami, H. (2014). Tropical cyclones in reanalysis data sets. Geophysical Research Letters, 41, 2133-2141. doi:10.1002/2014gl059519.

Onogi, K., Tsutsui, J., Koide, H., Sakamoto, M., Kobayashi, S., Hatsushika, H., Matsumoto, T., Yamazaki, N., Kamahori, H., Takahashi, K., Kadokura, S., Wada, K., Kato, K., Oyama, R., Ose, T., Mannoji, N., \& Taira, R. (2007). The jra-25 reanalysis. Journal of the Meteorological Society of Japan. Ser. II, 85, 369-432. doi:10.2151/jmsj.85.369.

Perez, J., Menendez, M., \& Losada, I. J. (2017). GOW2: A global wave hindcast for coastal applications. Coastal Engineering, 124, 1-11. doi:10.1016/j.coastaleng.2017.03.005.

Queffeulou, P., \& Croize-Fillon, D. (2015). Global altimeter SWH data set. Technical Report 11.1 IFREMER/CERSAT. URL: ftp://ftp.ifremer.fr/ifremer/cersat/products/swath/ altimeters/waves/documentation/altimeter_wave_merge__11.1.pdf.

Rascle, N., \& Ardhuin, F. (2013). A global wave parameter database for geophysical applications. part 2: Model validation with improved source term parameterization. Ocean Modelling, 70, 174-188. doi:10.1016/j.ocemod.2012.12.001.

Reynolds, R. W., Rayner, N. A., Smith, T. M., Stokes, D. C., \& Wang, W. (2002). An improved in situ and satellite SST analysis for climate. Journal of Climate, 15, 1609-1625. doi:10.1175/ 1520-0442(2002)015<1609:aiisas>2.0.co;2. 
Ricciardulli, L., \& Wentz, F. J. (2015). A scatterometer geophysical model function for climatequality winds: QuikSCAT ku-2011. Journal of Atmospheric and Oceanic Technology, 32, 18291846. doi:10.1175/jtech-d-15-0008.1.

Rienecker, M. M., Suarez, M. J., Gelaro, R., Todling, R., Bacmeister, J., Liu, E., Bosilovich, M. G., Schubert, S. D., Takacs, L., Kim, G.-K., Bloom, S., Chen, J., Collins, D., Conaty, A., da Silva, A., Gu, W., Joiner, J., Koster, R. D., Lucchesi, R., Molod, A., Owens, T., Pawson, S., Pegion, P., Redder, C. R., Reichle, R., Robertson, F. R., Ruddick, A. G., Sienkiewicz, M., \& Woollen, J. (2011). MERRA: NASA's modern-era retrospective analysis for research and applications. Journal of Climate, 24, 3624-3648. doi:10.1175/jcli-d-11-00015.1.

Rife, D. L., Pinto, J. O., Monaghan, A. J., Davis, C. A., \& Hannan, J. R. (2010). Global distribution and characteristics of diurnally varying low-level jets. Journal of Climate, 23, 5041-5064. doi:10. 1175/2010jcli3514.1.

Rife, D. L., Pinto, J. O., Monaghan, A. J., Davis, C. A., \& Hannan, J. R. (2014). Ncar global climate four-dimensional data assimilation (cfdda) hourly $40 \mathrm{~km}$ reanalysis. URL: https ://doi. org/10.5065/D6M32STK. doi:10.5065/D6M32STK.

Saha, S., Moorthi, S., Pan, H.-L., Wu, X., Wang, J., Nadiga, S., Tripp, P., Kistler, R., Woollen, J., Behringer, D., Liu, H., Stokes, D., Grumbine, R., Gayno, G., Wang, J., Hou, Y.-T., ya Chuang, H., Juang, H.-M. H., Sela, J., Iredell, M., Treadon, R., Kleist, D., Delst, P. V., Keyser, D., Derber, J., Ek, M., Meng, J., Wei, H., Yang, R., Lord, S., van den Dool, H., Kumar, A., Wang, W., Long, C., Chelliah, M., Xue, Y., Huang, B., Schemm, J.-K., Ebisuzaki, W., Lin, R., Xie, P., Chen, M., Zhou, S., Higgins, W., Zou, C.-Z., Liu, Q., Chen, Y., Han, Y., Cucurull, L., Reynolds, R. W., Rutledge, G., \& Goldberg, M. (2010). The NCEP climate forecast system reanalysis. Bulletin of the American Meteorological Society, 91, 1015-1058. doi:10.1175/2010bams3001.1.

Saha, S., Moorthi, S., Wu, X., Wang, J., Nadiga, S., Tripp, P., Behringer, D., Hou, Y.-T., ya Chuang, H., Iredell, M., Ek, M., Meng, J., Yang, R., Mendez, M. P., van den Dool, H., Zhang, Q., Wang, W., Chen, M., \& Becker, E. (2014). The NCEP climate forecast system version 2. Journal of Climate, 27, 2185-2208. doi:10.1175/jcli-d-12-00823.1.

Stickler, A., Brnnimann, S., Valente, M. A., Bethke, J., Sterin, A., Jourdain, S., Roucaute, E., Vasquez, M. V., Reyes, D. A., Allan, R., \& Dee, D. (2014). ERA-CLIM: Historical surface 
and upper-air data for future reanalyses. Bulletin of the American Meteorological Society, 95, 1419-1430. doi:10.1175/bams-d-13-00147.1.

Stopa, J. E., Ardhuin, F., Babanin, A., \& Zieger, S. (2016a). Comparison and validation of physical wave parameterizations in spectral wave models. Ocean Modelling, 103, 2-17. doi:10.1016/j. ocemod.2015.09.003.

Stopa, J. E., Ardhuin, F., \& Girard-Ardhuin, F. (2016b). Wave climate in the arctic 1992-2014: seasonality and trends. The Cryosphere, 10, 1605-1629. doi:10.5194/tc-10-1605-2016.

Stopa, J. E., Ardhuin, F., Husson, R., Jiang, H., Chapron, B., \& Collard, F. (2016c). Swell dissipation from 10 years of envisat advanced synthetic aperture radar in wave mode. Geophysical Research Letters, 43, 3423-3430. doi:10.1002/2015gl067566.

Stopa, J. E., \& Cheung, K. F. (2014). Intercomparison of wind and wave data from the ECMWF reanalysis interim and the NCEP climate forecast system reanalysis. Ocean Modelling, 75, 65-83. doi:10.1016/j.ocemod.2013.12.006.

Thomson, J., Fan, Y., Stammerjohn, S., Stopa, J., Rogers, W. E., Girard-Ardhuin, F., Ardhuin, F., Shen, H., Perrie, W., Shen, H., Ackley, S., Babanin, A., Liu, Q., Guest, P., Maksym, T., Wadhams, P., Fairall, C., Persson, O., Doble, M., Graber, H., Lund, B., Squire, V., Gemmrich, J., Lehner, S., Holt, B., Meylan, M., Brozena, J., \& Bidlot, J.-R. (2016). Emerging trends in the sea state of the beaufort and chukchi seas. Ocean Modelling, 105, 1-12. doi:10.1016/j.ocemod. 2016.02 .009

Tolman, H. L. (2002). Alleviating the garden sprinkler effect in wind wave models. Ocean Modelling, 4, 269-289. doi:10.1016/s1463-5003(02)00004-5.

Uppala, S. M., KÅllberg, P. W., Simmons, A. J., Andrae, U., Bechtold, V. D. C., Fiorino, M., Gibson, J. K., Haseler, J., Hernandez, A., Kelly, G. A., Li, X., Onogi, K., Saarinen, S., Sokka, N., Allan, R. P., Andersson, E., Arpe, K., Balmaseda, M. A., Beljaars, A. C. M., Berg, L. V. D., Bidlot, J., Bormann, N., Caires, S., Chevallier, F., Dethof, A., Dragosavac, M., Fisher, M., Fuentes, M., Hagemann, S., Hólm, E., Hoskins, B. J., Isaksen, L., Janssen, P. A. E. M., Jenne, R., Mcnally, A. P., Mahfouf, J.-F., Morcrette, J.-J., Rayner, N. A., Saunders, R. W., Simon, P., Sterl, A., Trenberth, K. E., Untch, A., Vasiljevic, D., Viterbo, P., \& Woollen, J. (2005). 
The ERA-40 re-analysis. Quarterly Journal of the Royal Meteorological Society, 131, 2961-3012.

728 doi:10.1256/qj .04.176. 
Table 1: Summary of wind datasets used to generate wave hindcasts in this study.

\begin{tabular}{|c|c|c|c|c|c|c|c|}
\hline Name & Institution & Spatial Resolution & $\begin{array}{l}\text { Time } \\
\text { reso- } \\
\text { lution }\end{array}$ & Period & Assimilation & Ice & References \\
\hline $\mathrm{R} 1$ & NCEP & $1.875^{\circ} \times 1.875^{\circ}$ & $6 \mathrm{~h}$ & 1948-present & 3D-VAR & Yes & Kalnay et al. (1996) \\
\hline CFSR & NCEP & $\begin{array}{l}0.3^{\circ} \times 0.3^{\circ}(\mathrm{v} 1) \\
0.2^{\circ} \times 0.2^{\circ}(\mathrm{v} 2)\end{array}$ & $1 \mathrm{~h}$ & 1979-present & 3D-VAR & Yes & Saha et al. $(2010,2014)$ \\
\hline $\mathrm{R} 20 \mathrm{C}$ & NCEP & $1.875^{\circ} \times 1.875^{\circ}$ & $3 \mathrm{~h}$ & 1851-present & $\begin{array}{l}\text { Kalman Fil- } \\
\text { ter }\end{array}$ & Yes & Compo et al. (2011) \\
\hline ERA40 & ECMWF & $1.125^{\circ} \times 1.125^{\circ}$ & $6 \mathrm{~h}$ & $1957-2002$ & 3D-VAR & Yes & Uppala et al. (2005) \\
\hline ERAI & ECMWF & $0.75^{\circ} \times 0.75^{\circ}$ & $6 \mathrm{~h}$ & 1979-present & $4 \mathrm{D}-\mathrm{VAR}$ & Yes & Dee et al. (2011) \\
\hline ERA20C & ECMWF & $1.125^{\circ} \times 1.125^{\circ}$ & $6 \mathrm{~h}$ & $1900-2011$ & 4D-VAR & Yes & Stickler et al. (2014) \\
\hline JRA25 & JMA & $1.125^{\circ} \times 1.125^{\circ}$ & $6 \mathrm{~h}$ & $1979-2014$ & 3D-VAR & Yes & Onogi et al. (2007) \\
\hline JRA55 & JMA & $0.5625^{\circ} \times 0.5625^{\circ}$ & $3 \mathrm{~h}$ & 1958-present & $4 \mathrm{D}-\mathrm{VAR}$ & Yes & Kobayashi et al. (2015) \\
\hline MERRA & NASA & $0.5^{\circ} \times 0.625^{\circ}(\mathrm{v} 2)$ & $1 \mathrm{~h}$ & 1980-present & 3D-VAR & Yes & Molod et al. (2015) \\
\hline CFDDA & NCAR & $0.4^{\circ} \times 0.4^{\circ}$ & $1 \mathrm{~h}$ & $1985-2005$ & $4 \mathrm{D}-\mathrm{VAR}$ & No: use R1 & $\begin{array}{l}\text { Rife et al. (2010); Rife } \\
\text { et al. (2014) }\end{array}$ \\
\hline CCMP & RSS & $0.25^{\circ} \times 0.25^{\circ}$ & $6 \mathrm{~h}$ & 1987-present & Scat/Rad & No: use SSMI* & Atlas et al. (2011) \\
\hline $\mathrm{SCT}$ & IFREMER & $0.25^{\circ} \times 0.25^{\circ}$ & $6 \mathrm{~h}$ & 1993-present & Scat & No: use SSMI* & Bentamy et al. (2016) \\
\hline
\end{tabular}


Table 2: Error metrics comparing 12 hindcasts with altimeter $H_{s}$ for all sea states and only when $H_{s}>10 \mathrm{~m}($ values in parenthesis) for 2001. The number of altimeter observations is 10767248 and 8850 for all observations and $H_{s}>10$ $\mathrm{m}$ respectively. The $\beta_{M A X}$ given in the second column is the calibrated value used for the hindcast.

\begin{tabular}{|l||l||l|l|l|l|}
\hline Name & $\beta_{\text {MAX }}$ & Bias $(\mathrm{m})$ & RMSE $(\mathrm{m})$ & SI $(\%)$ & Lin. Slope \\
\hline R1 & 1.750 & $-0.05(-1.94)$ & $0.64(2.62)$ & $23.85(15.81)$ & $0.91(0.55)$ \\
ERA40 & 2.050 & $+0.00(-1.08)$ & $0.43(1.57)$ & $15.96(10.16)$ & $0.97(0.78)$ \\
JRA25 & 1.500 & $-0.05(-1.11)$ & $0.49(2.05)$ & $18.22(15.44)$ & $0.95(0.81)$ \\
CFSR & 1.385 & $+0.01(-0.42)$ & $0.35(1.19)$ & $13.15(9.98)$ & $0.95(0.88)$ \\
ERAI & 1.660 & $-0.02(-0.91)$ & $0.38(1.37)$ & $14.13(9.14)$ & $0.98(0.69)$ \\
JRA55 & 1.215 & $-0.06(-0.49)$ & $0.41(1.27)$ & $15.26(10.46)$ & $0.98(0.86)$ \\
MERRA & 1.630 & $-0.06(+0.24)$ & $0.36(1.22)$ & $13.26(10.72)$ & $0.97(1.06)$ \\
CFDDA & 2.550 & $-0.09(-3.30)$ & $0.87(3.96)$ & $32.05(19.60)$ & $0.73(0.73)$ \\
R20C & 1.100 & $-0.09(-1.54)$ & $0.66(2.67)$ & $24.48(19.54)$ & $0.94(0.65)$ \\
ERA20C & 1.710 & $-0.00(-2.52)$ & $0.68(3.46)$ & $25.36(21.27)$ & $0.89(0.50)$ \\
CCMP & 1.300 & $-0.06(+0.33)$ & $0.33(1.30)$ & $12.20(11.29)$ & $0.95(1.14)$ \\
SCT & 1.490 & $-0.04(+0.10)$ & $0.35(1.48)$ & $12.95(13.26)$ & $0.95(1.14)$ \\
\hline
\end{tabular}




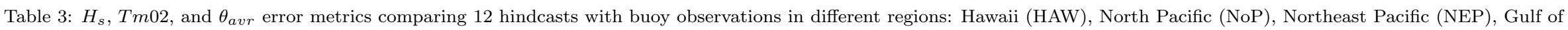

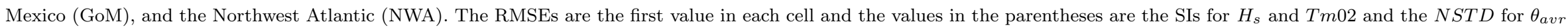

\begin{tabular}{|c|c|c|c|c|c|c|c|c|c|c|c|c|}
\hline \multirow{3}{*}{$\begin{array}{l}\text { Name } \\
\mathrm{N}\end{array}$} & \multicolumn{5}{|l|}{$H_{s}(\mathrm{~m})$} & \multicolumn{5}{|c|}{ Tm02 (s) } & \multicolumn{2}{|c|}{$\theta_{\text {avr }}(\mathrm{deg})$} \\
\hline & HAW & NoP & NEP & GoM & NWA & HAW & NoP & NEP & GoM & NWA & NEP & GoM \\
\hline & 34047 & 19683 & 134589 & 37018 & 31022 & 34047 & 19683 & 134589 & 37018 & 31022 & 8639 & 37018 \\
\hline $\mathrm{R} 1$ & $0.39(13)$ & $0.78(25)$ & $0.68(29)$ & $0.64(37)$ & $0.45(25)$ & $0.97(9)$ & $0.99(11)$ & 1.61(19) & $1.74(19)$ & $1.03(12)$ & $30(-41)$ & $53(0)$ \\
\hline ERA40 & $0.23(10)$ & $0.38(12)$ & $0.59(24)$ & $0.58(31)$ & $0.29(15)$ & $0.84(7)$ & $0.84(6)$ & $1.49(19)$ & $1.75(17)$ & $1.05(9)$ & $31(-40)$ & $53(1)$ \\
\hline JRA25 & $0.29(9)$ & $0.47(15)$ & $0.56(24)$ & $0.58(31)$ & $0.31(17)$ & $0.76(7)$ & $0.77(7)$ & $1.37(16)$ & $1.74(18)$ & $0.89(9)$ & $32(-27)$ & $52(-0)$ \\
\hline CFSR & $0.27(11)$ & $0.36(12)$ & $0.54(23)$ & $0.55(30)$ & $0.29(16)$ & $0.71(8)$ & $0.69(6)$ & $1.34(15)$ & $1.60(17)$ & $0.82(8)$ & $32(-23)$ & $52(-1)$ \\
\hline ERAI & $0.27(9)$ & $0.43(14)$ & $0.57(24)$ & $0.60(33)$ & $0.31(15)$ & $0.81(6)$ & $0.80(7)$ & $1.36(17)$ & $1.77(17)$ & $1.01(9)$ & $31(-36)$ & $51(4)$ \\
\hline JRA55 & $0.39(10)$ & $0.44(14)$ & $0.56(23)$ & $0.62(34)$ & $0.33(17)$ & $0.82(7)$ & $0.72(7)$ & $1.42(16)$ & $1.74(18)$ & $0.98(9)$ & $32(-24)$ & $51(4)$ \\
\hline MERRA & $0.35(11)$ & $0.41(13)$ & $0.55(23)$ & $0.58(31)$ & $0.31(16)$ & $0.84(8)$ & $0.80(6)$ & $1.42(16)$ & $1.74(17)$ & $0.98(8)$ & $32(-28)$ & $53(-0)$ \\
\hline CFDDA & $0.53(19)$ & $1.29(37)$ & $0.89(36)$ & $0.69(41)$ & $0.50(23)$ & $0.87(10)$ & $1.91(20)$ & $2.06(23)$ & $1.51(19)$ & $0.82(10)$ & $33(-2)$ & $54(-10)$ \\
\hline $\mathrm{R} 20 \mathrm{C}$ & $0.40(13)$ & $0.65(20)$ & $0.60(26)$ & $0.56(31)$ & $0.48(25)$ & $0.93(9)$ & $0.84(10)$ & $1.58(20)$ & $1.57(18)$ & $1.05(13)$ & $30(-43)$ & $59(-7)$ \\
\hline ERA20C & $0.29(12)$ & $0.59(19)$ & $0.61(27)$ & $0.55(30)$ & $0.40(22)$ & $0.83(8)$ & $0.89(9)$ & $1.64(19)$ & $1.61(17)$ & $1.03(11)$ & $28(-42)$ & $56(-6)$ \\
\hline CCMP & $0.26(10)$ & $0.40(12)$ & $0.54(23)$ & $0.55(30)$ & $0.30(15)$ & $0.76(8)$ & $0.81(6)$ & $1.43(17)$ & $1.66(17)$ & $0.97(8)$ & $34(-17)$ & $52(0)$ \\
\hline $\mathrm{SCT}$ & $0.22(9)$ & $0.40(11)$ & $0.56(23)$ & $0.56(30)$ & $0.33(18)$ & $0.72(7)$ & $0.87(6)$ & $1.45(18)$ & $1.68(17)$ & $0.96(10)$ & $34(-19)$ & $53(-1)$ \\
\hline
\end{tabular}


Table 4: Summary: qualitative wave hindcast performances using different forcing fields.

\begin{tabular}{|c|c|c|}
\hline Name & Advantages & Disadvantages \\
\hline & \multicolumn{2}{|c|}{ Static Reanalyzes } \\
\hline ERA40 & $\begin{array}{l}\text { position of storms is accurate; performs the } \\
\text { best for a 1st generation reanalysis; }\end{array}$ & course resolution; underestimates extremes \\
\hline JRA25 & position of storms is accurate; & underestimates extremes \\
\hline \multirow[t]{2}{*}{ CFDDA } & high resolution; NCEP's only 4D-Var & $\begin{array}{l}\text { strongly underestimates extremes; poor per- } \\
\text { formance inaccurate for wave hindcasting }\end{array}$ \\
\hline & \multicolumn{2}{|c|}{ Active Reanalyzes } \\
\hline $\mathrm{R} 1$ & $\begin{array}{l}\text { long time series; no model or assimilation } \\
\text { changes to reanalysis }\end{array}$ & $\begin{array}{l}\text { course resolution; position of storms is incor- } \\
\text { rect; worst accuracy and precision }\end{array}$ \\
\hline CFSR & $\begin{array}{l}\text { high resolution; 1-hour time step; captures ex- } \\
\text { tremes; best performance of } T m 02\end{array}$ & $\begin{array}{l}\text { imprecise; storm location can be inaccurate; } \\
\text { inconsistent between v1 and v2; }\end{array}$ \\
\hline ERAI & $\begin{array}{l}\text { highly precise (lowest SIs); position of storms } \\
\text { is accurate }\end{array}$ & $\begin{array}{l}\text { underestimates extremes; } 6 \mathrm{~h} \text { time step can } \\
\text { miss important events }\end{array}$ \\
\hline JRA55 & $\begin{array}{l}\text { long time series; captures extremes; incorpo- } \\
\text { ration of tropical cyclones }\end{array}$ & $\begin{array}{l}\text { underestimates peaks of extremes; tropics } \\
\text { have reduced performance }\end{array}$ \\
\hline \multirow[t]{2}{*}{ MERRA } & $\begin{array}{l}\text { captures extremes; } 1 \text {-hour time step; continual } \\
\text { efforts to improve; }\end{array}$ & overestimates peaks of extremes \\
\hline & \multicolumn{2}{|c|}{ 20th-century Reanalyzes } \\
\hline \multirow[t]{2}{*}{$\begin{array}{l}\text { R20C } \\
\text { ERA20C }\end{array}$} & $\begin{array}{l}+100 \text {-yr time series; captures overall climate } \\
\text { variability; less sensitive to changes of the data } \\
\text { assimilated; captures extra-tropical extremes }\end{array}$ & $\begin{array}{l}\text { R20C overestimates extra-tropical storms; } \\
\text { coarse resolution; } 6 \text { h time step can miss im- } \\
\text { portant events; tropical storms poorly cap- } \\
\text { tured; reduced accuracy and precision; worse } \\
\text { performance in Southern Hemisphere }\end{array}$ \\
\hline & \multicolumn{2}{|c|}{ Satellite Wind Fields } \\
\hline $\begin{array}{l}\text { CCMP } \\
\text { SCT }\end{array}$ & $\begin{array}{l}\text { lowest } H_{s} \text { RMSEs; high spatial resolution; in- } \\
\text { dependent of a model; captures extremes well }\end{array}$ & $\begin{array}{l}\text { shorter time series; interpolation and } 6 \mathrm{~h} \text { time } \\
\text { step can create unphysical storm positions and } \\
\text { miss important events }\end{array}$ \\
\hline
\end{tabular}



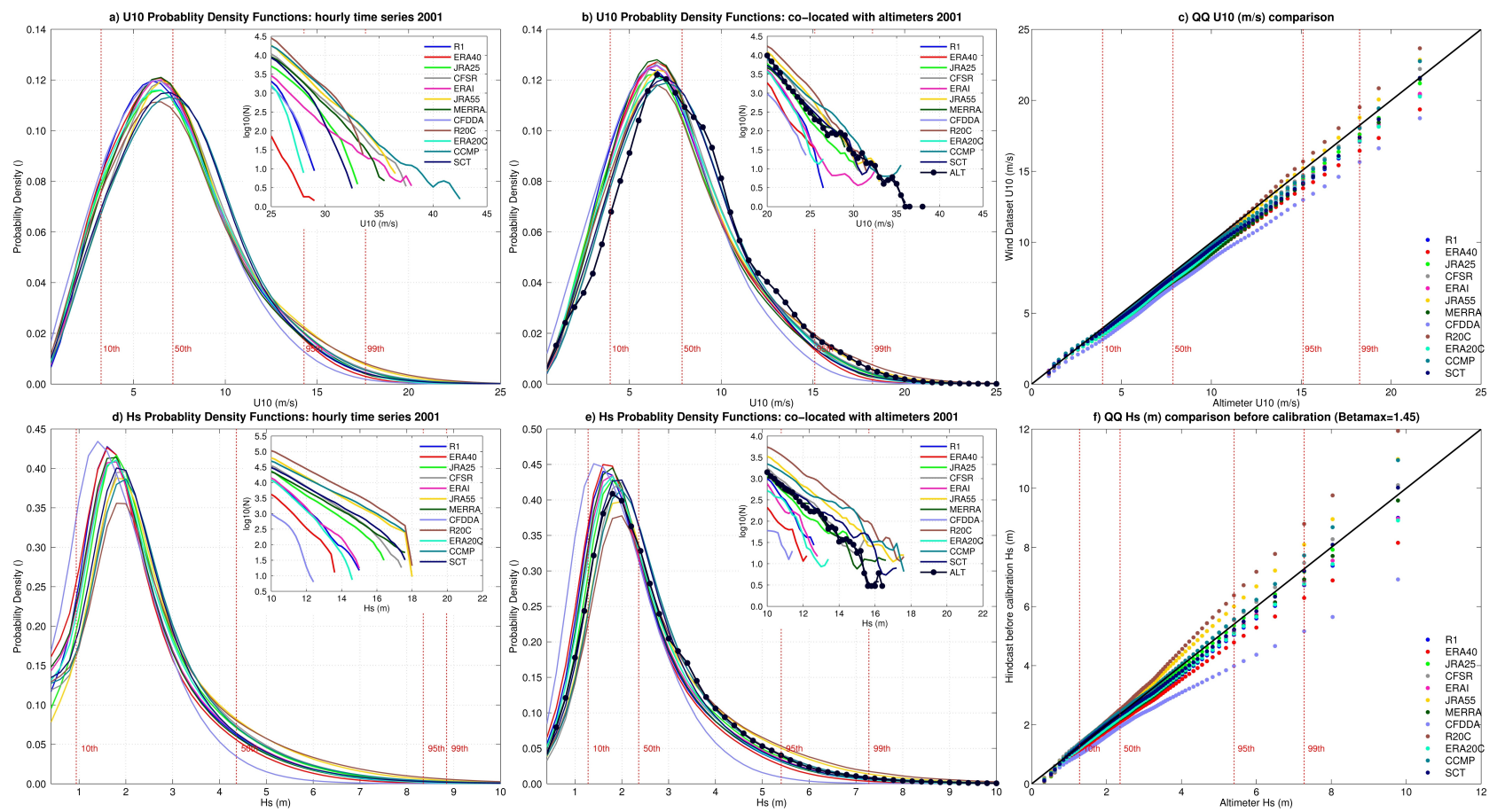

Figure 1: Probability density functions and quantile-quantile plots of surface wind speeds (U10) and significant wave heights $\left(H_{s}\right)$ for different wind products $(\mathrm{a}, \mathrm{b}, \mathrm{c})$ and wave output using the same physical parameterization (d,e,f) within WAVEWATCH for the year of 2001. The left panels display the output from the full hourly time series interpolated to the $0.5^{\circ}$ wave model grid for U10 (a) and $H_{s}$ output from the model (d). The middle panels display the model U10 (b) and $H_{s}$ (e) co-located with the merged altimeters. The y-axis in the zoomed upper right sub-panels of (a), (b), (d), and (e) are logarithm of the number of observations $N$ (e.g. $\log (N))$. The right panels display the quantile-quantile plots for U10 (c) and $H_{s}$ (f). 

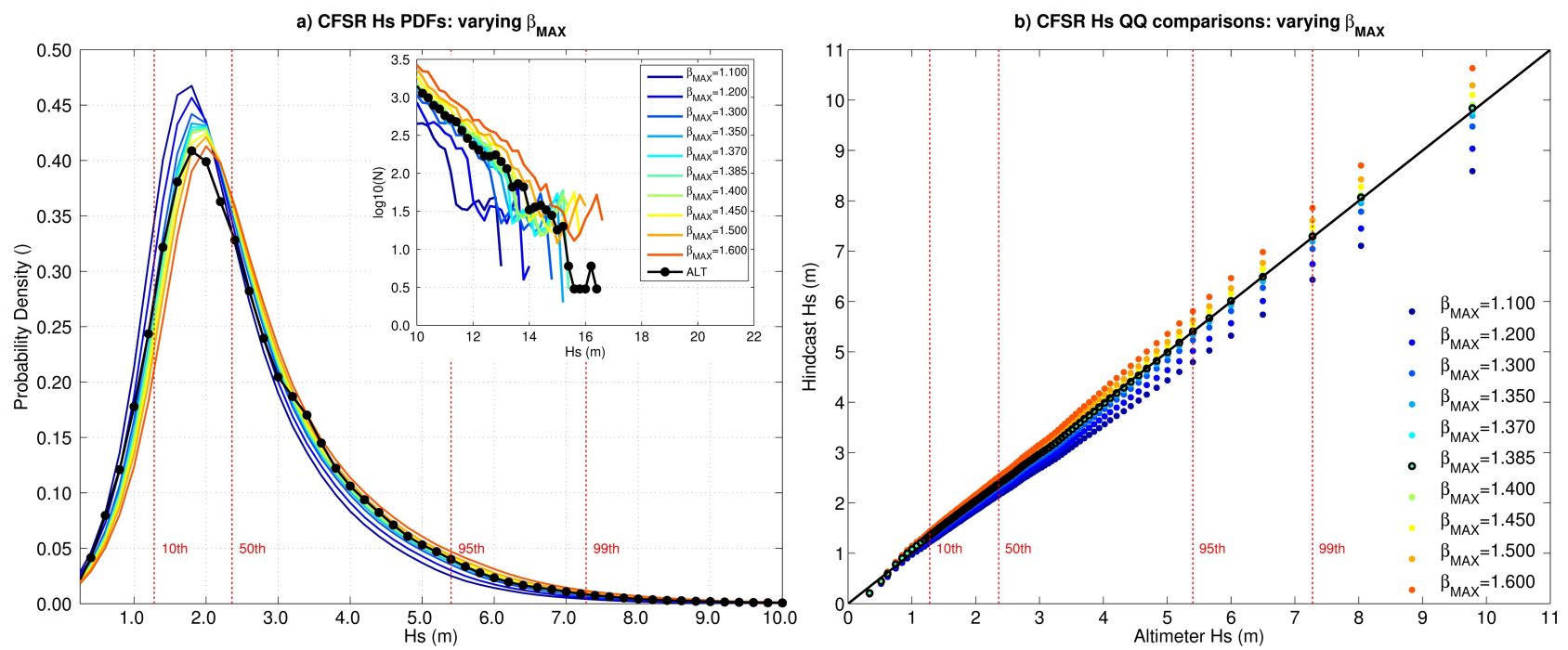

Figure 2: $H_{s}$ PDFs (a) and QQ (b) plots created by modifying the wind to wave growth parameter $\beta_{M A X}$ and using the CFSR winds as input. The altimeter observations in black are given for reference in (a). 

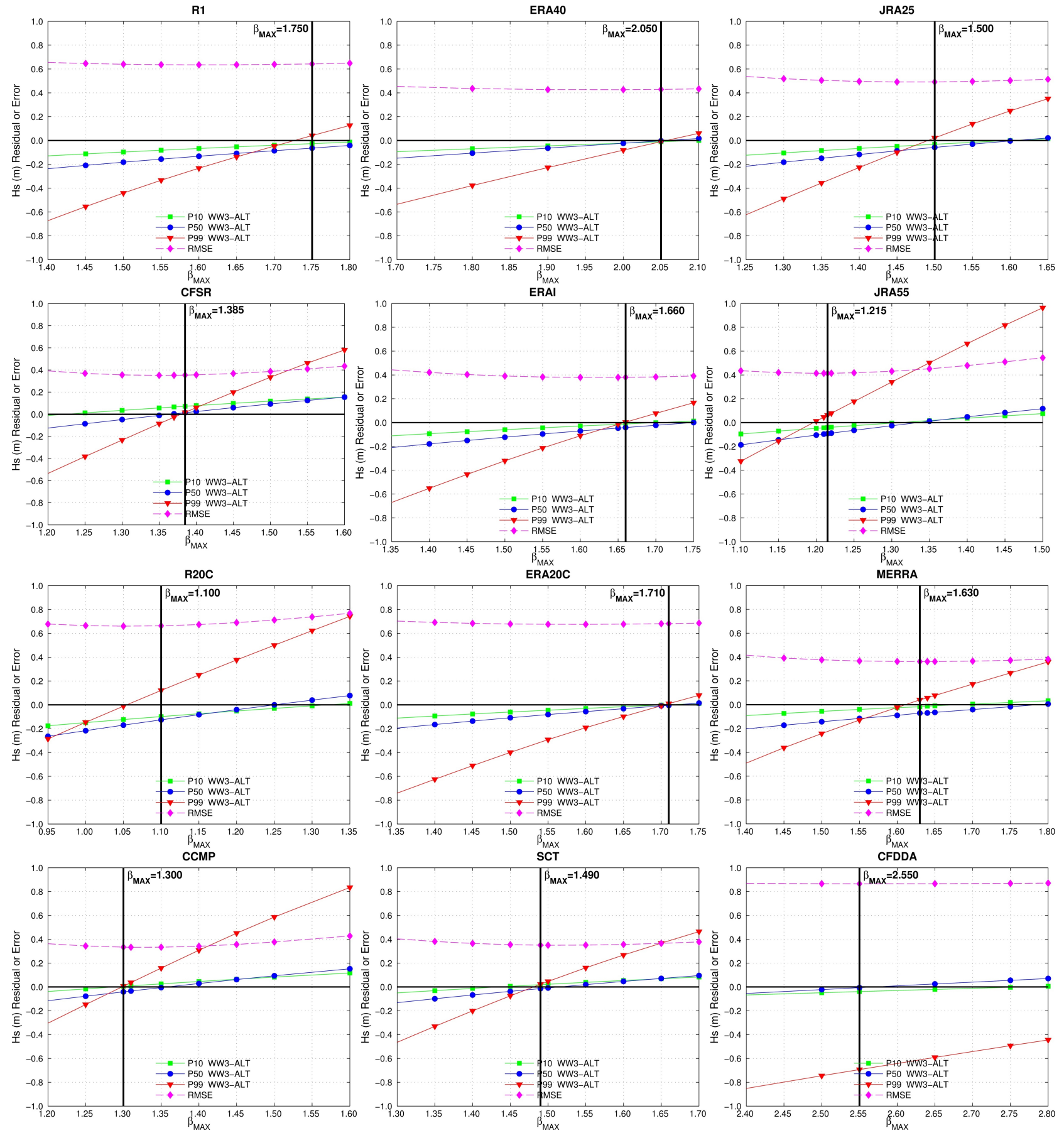

Figure 3: Calibration of the wind datasets based on modifying $\beta_{M A X}$ and comparing to altimeter $H_{s}$. The green line with squares is the P10 (WW3-ALT), the blue line with circles is the median (P50), the red line with triangles is the P99 (WW3-ALT)), and the magenta dashed line with diamonds is the root mean square error. The chosen $\beta_{M A X}$ value is specified by the vertical black line. 

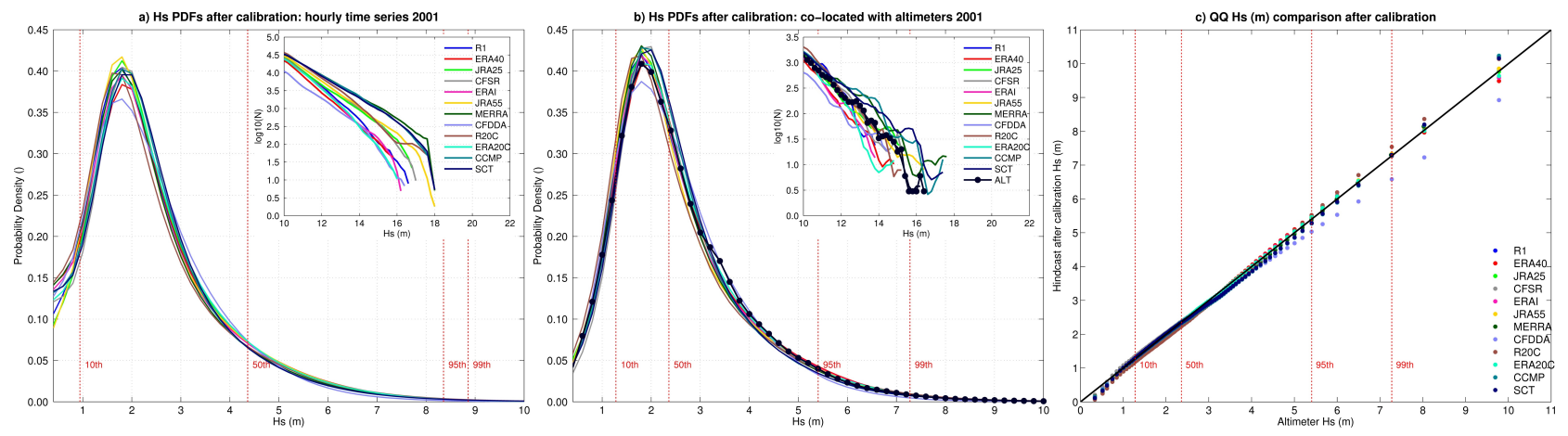

Figure 4: $H_{s} \operatorname{PDFs}(\mathrm{a}, \mathrm{b})$ and QQ plots (c) for 12 wind datasets (color) using an optimal value for $\beta_{M A X}$ and comparing to the altimeter observations (black in $\mathrm{b}$ ). The $\beta_{M A X}$ was chosen by reducing the differences in the P50 and P99 and ensuring P99 is not underestimated. 


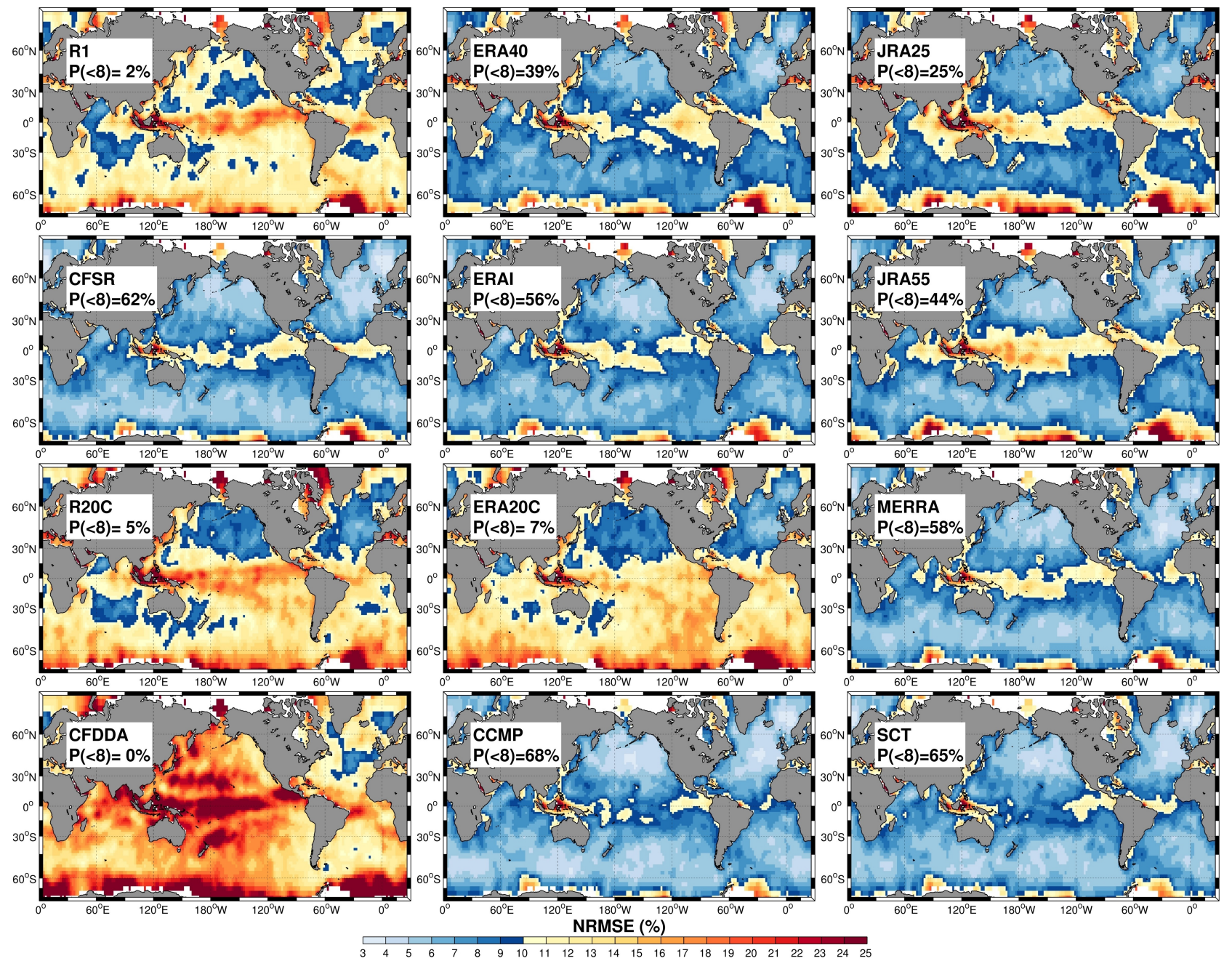

Figure 5: The normalized root mean square error of the significant wave height using the satellite altimeters as reference for 2001 in $2^{\circ}$ bins. The percentage of oceans that have a NRMSE $<8 \%$ is given for each hindcast. 


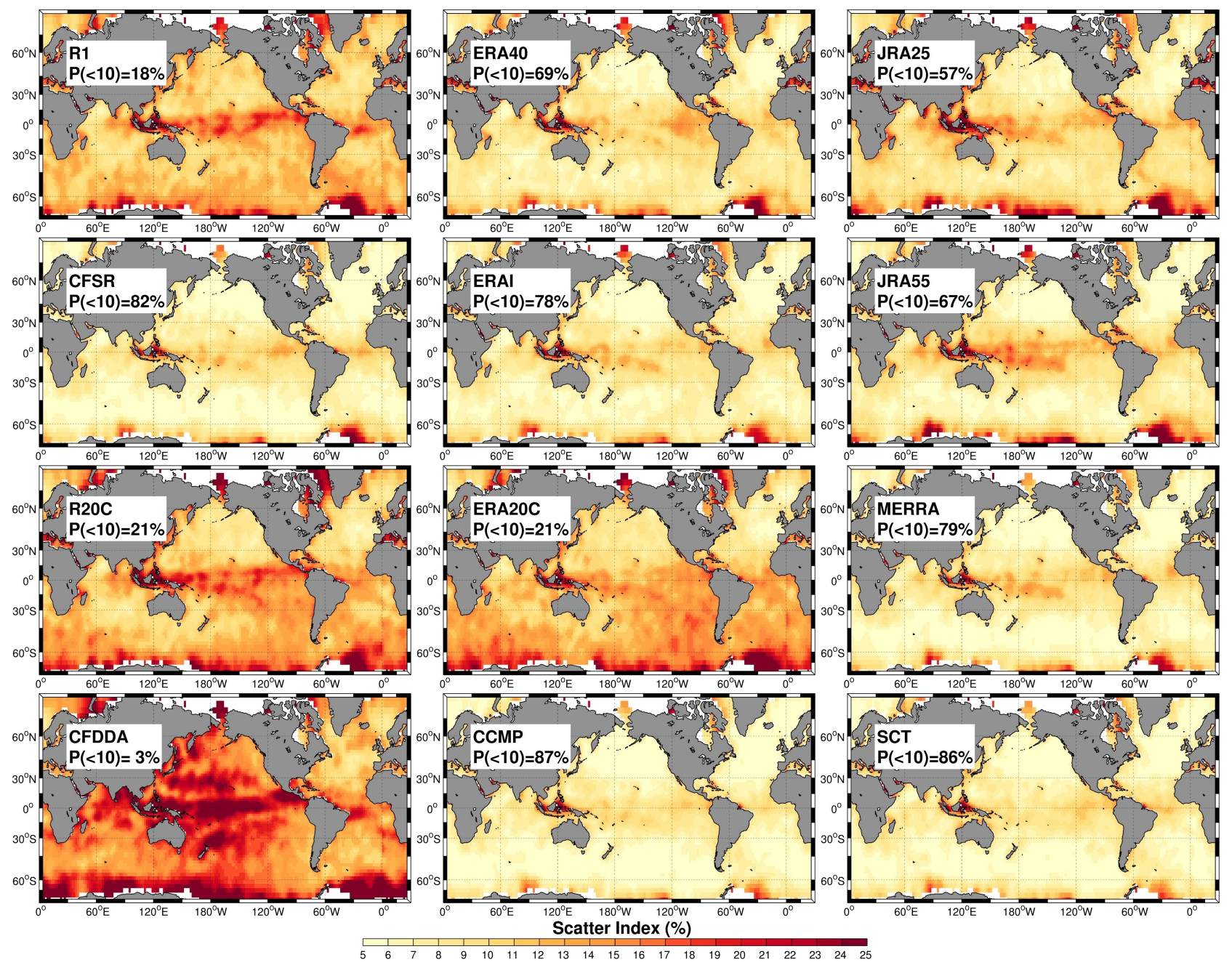

Figure 6: The scatter index (SI) of the significant wave height using the satellite altimeters as reference for 2001 in $2^{\circ}$ bins. The percentage of oceans that have a SI $<10 \%$ is given for each hindcast. 

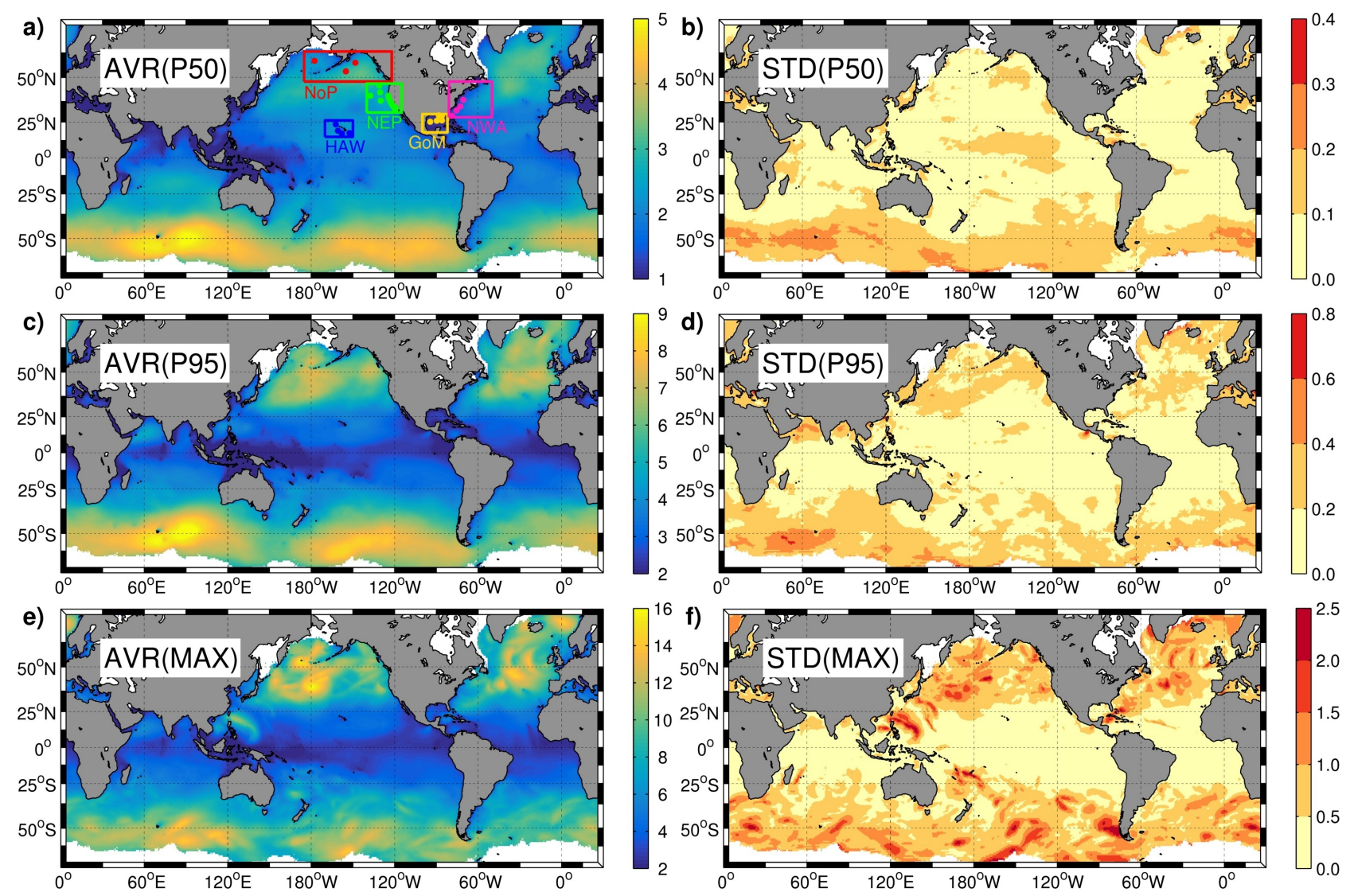

Figure 7: The average (a,c,e) and standard deviation (b,d,f) for different $H_{s}$ percentiles (P50 and P95) and the maximum for 2001 using the 11 different hindcasts excluding CFDDA. Colors denote values are in meters. Panel (a) shows the NDBC buoy locations in five regions: Hawaii (HAW), North Pacific (NoP), Northeast Pacific (NEP), Gulf of Mexico (GoM), and the Northwest Atlantic (NWA). 


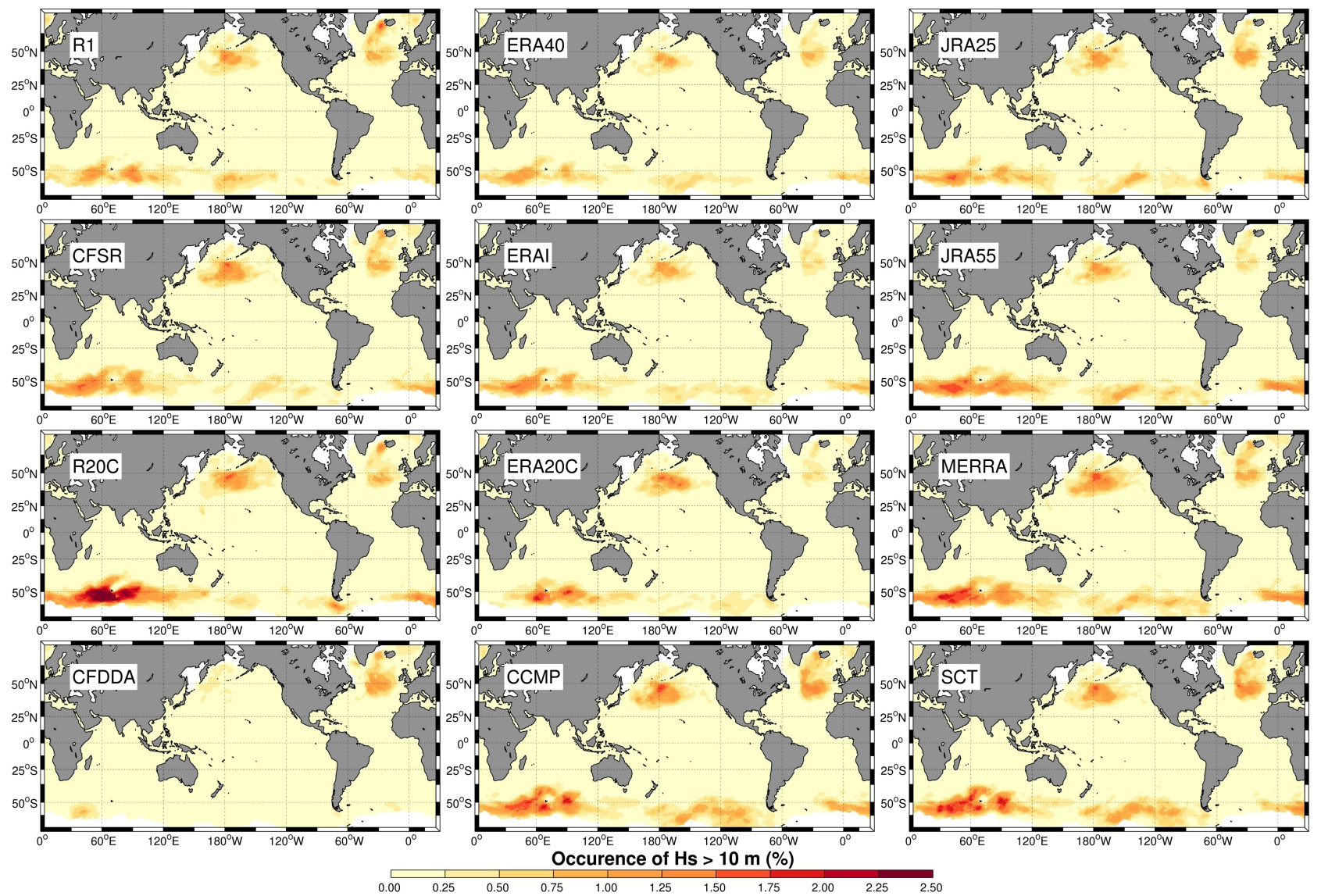

Figure 8: The occurrence the number of events with $H_{s}$ larger than $10 \mathrm{~m}$ for 2001 . This is based on hourly output from the hindcasts. 

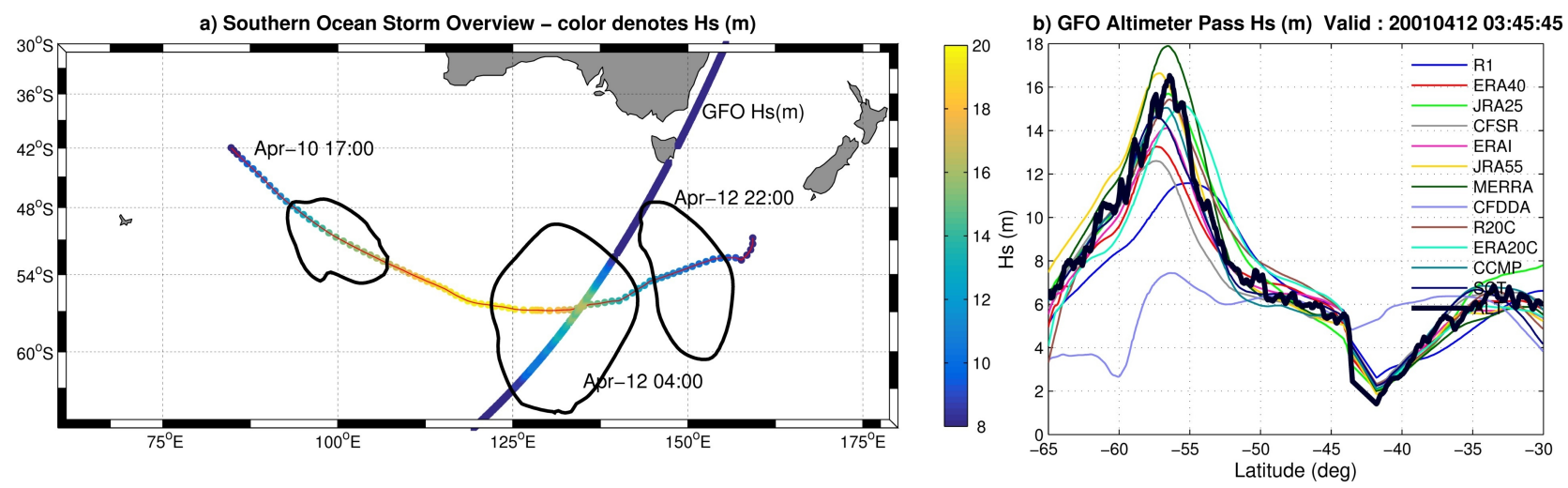

c) Contour Hs=9 m Valid: 20010410 17:00:00

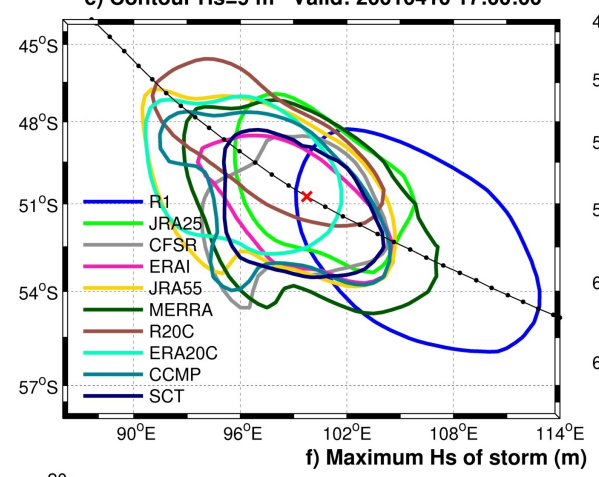

d) Contour Hs=9 m Valid: 20010412 04:00:00

e) Contour Hs=9 m Valid: 20010412 22:00:00
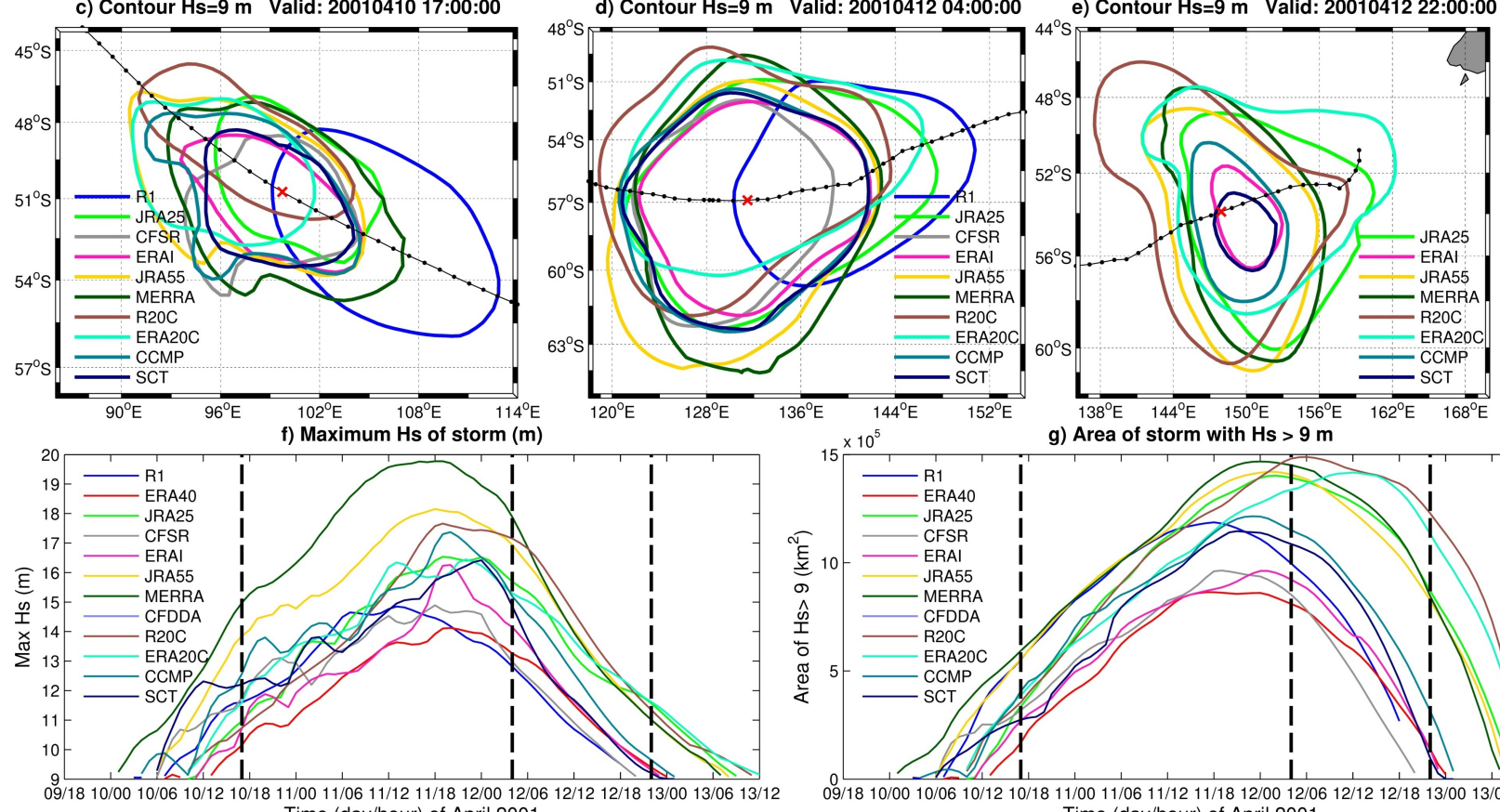

g) Area of storm with $\mathrm{Hs}>9 \mathrm{~m}$

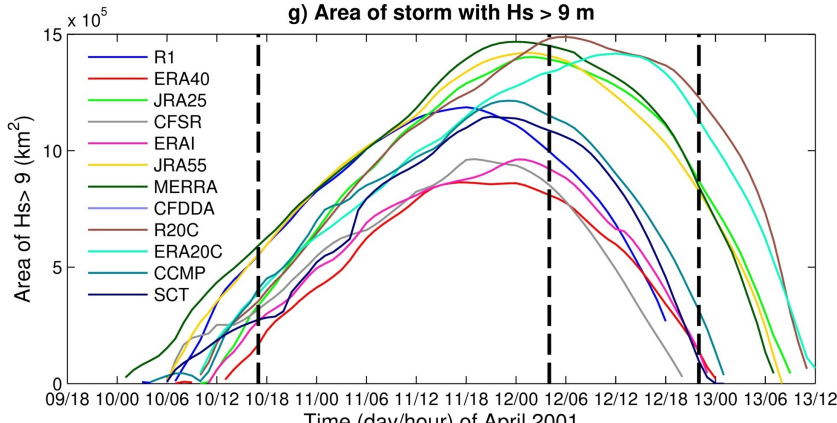

Time (day/hour) of April 2001

Figure 9: Extra-tropical storm in the Southern Ocean from April 10 to 13 2001. a) shows the storm track with $H_{s}$ taken from the MERRA driven wave hindcast. Three representative time periods are highlighted on April 10 at 1200 , April 12 at 0400, and April 12 at 2200. The contours represent $H_{s}=9 \mathrm{~m}$ using the MERRA-driven wave hindcast. The altimeter aboard GFO intersects the storm center on April 12 at 0345 . b) shows the GFO altimeter transect and the 12 other wave hidncasts. c,d,e) show the contours with $H_{s}=9 \mathrm{~m}$ for the representative phases of the storm. f) shows the maximum $H_{s}$ for the different hindcasts and g shows the area of the storm with $H_{s}>9 \mathrm{~m}$. 


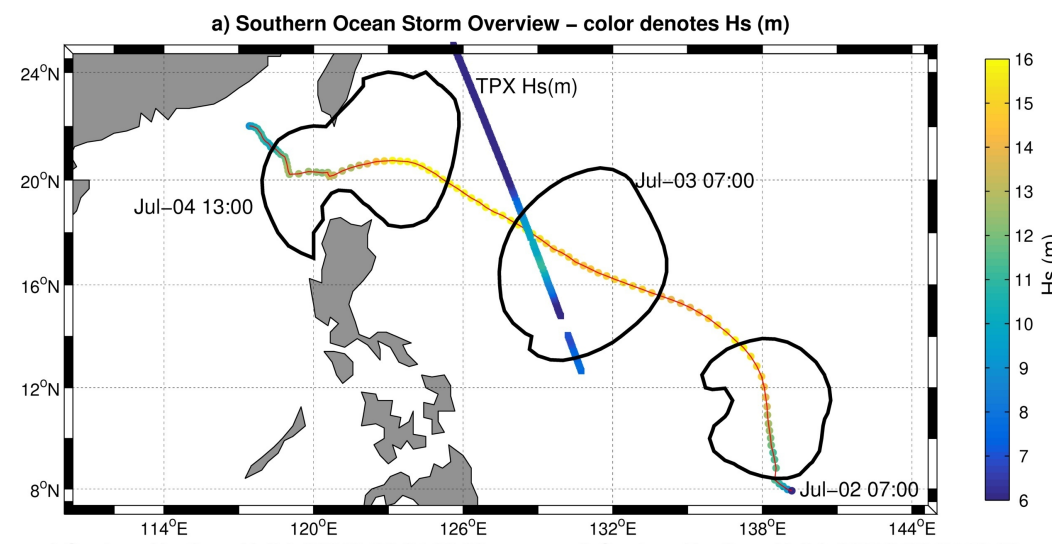

b) TPX Altimeter Pass Hs (m) Valid : 20010703 07:11:37
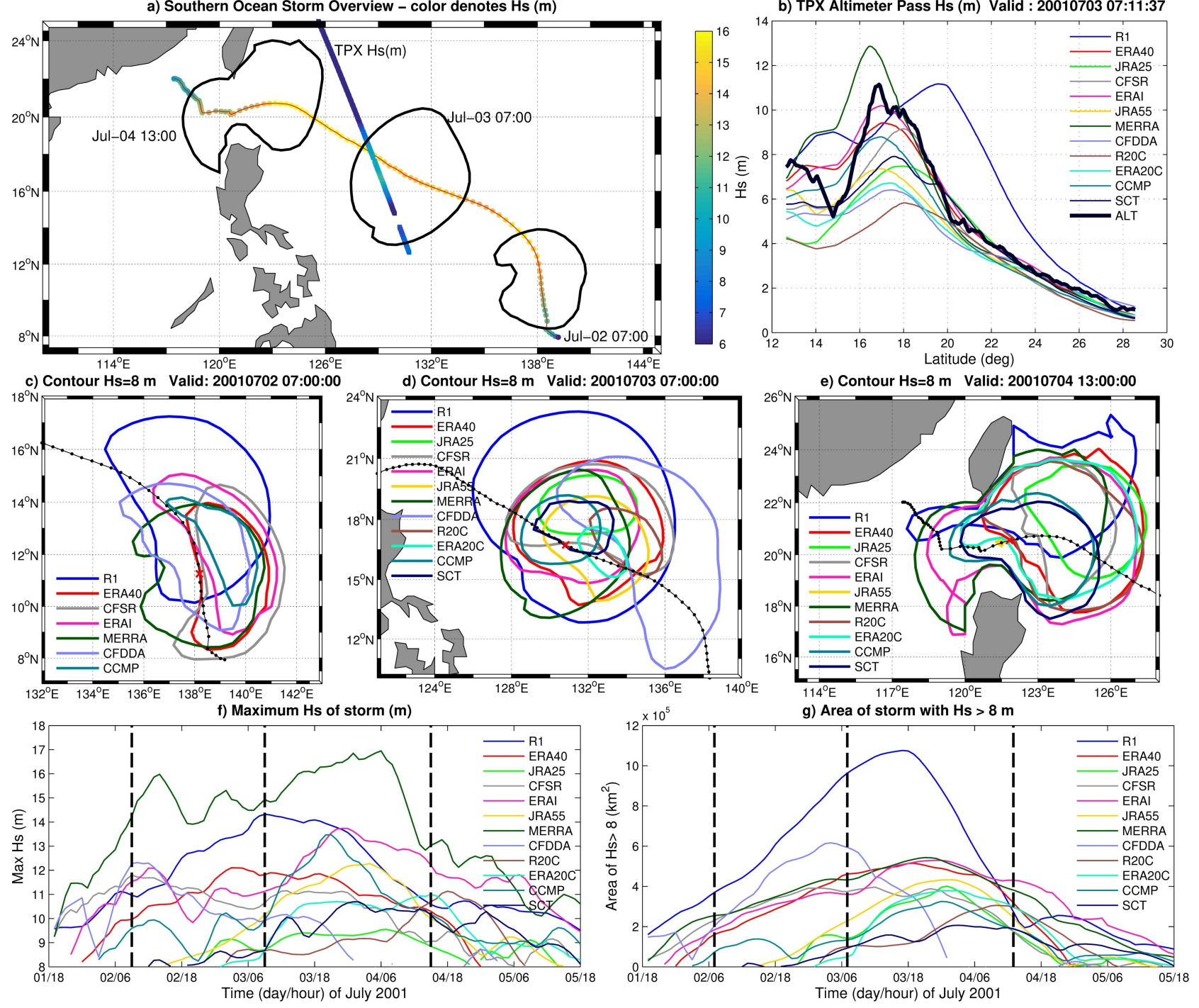

Figure 10: Tropical cyclone Utor in the Western Pacific Ocean from July 1 to 5 2001. a) shows the storm track with $H_{s}$ taken from the MERRA driven wave hindcast. Three representative time periods are highlighted on July 2 at 0700, July 3 at 0700, and July 4 at 1300. The contours represent $H_{s}=8 \mathrm{~m}$ using the MERRA-driven wave hindcast. The altimeter aboard TPX intersects the storm center on July 3 at 0711. b) shows the TPX altimeter transect and the 12 other wave hindcasts. c,d,e) show the contours with $H_{s}=8 \mathrm{~m}$ for the representative phases of the storm. f) shows the maximum $H_{s}$ for the different hindcasts and g shows the area of the storm with $H_{s}>8 \mathrm{~m}$. 